\title{
Los hermanos Estuardo y los Wautier. Retratos de una familia real en el exilio
}

\author{
The Stuarts and the Wautier Siblings. Portraits of a Royal \\ Family in Exile
}

\section{Jahel Sanzsalazar $^{1}$}

Resumen: El presente artículo examina la relación de los hermanos pintores del siglo XVII, Michaelina (Mons, 1604-Bruselas, 1689) y Charles Wautier (Mons, 1609- Bruselas, 1703), con los tres hijos mayores de Carlos I de Inglaterra, en el contexto previo a la restauración de la soberanía de los Estuardo en Gran Bretaña, mientras estaban en Bruselas, en el exilio. Junto al ya conocido Retrato de James, duque de York (Londres, 1633-1701), por Charles Wautier, se somete a investigación un anónimo retrato de dama vestida de rojo que se identifica con Mary Stuart, Princesa Real de Inglaterra y Princesa de Orange (Londres, 16311660), quien habría posado para la hermana de Charles, Michaelina, a principios de 1660 , cuando es posible localizarla en Bruselas, pocos meses antes de su temprana muerte. El significativo hallazgo refuerza la relación de los Wautier con los Estuardo y nos invita a considerar un retrato del hermano mayor y pronto rey, Carlos II (Londres, 1630-1685), realizado en las mismas circunstancias.

Palabras clave: Retrato; siglo XVII; Pintura flamenca; Bruselas; Wautier; pintora; Van Dyck; Estuardo; Orange; Carlos II; Restauración inglesa

\begin{abstract}
The present article examines the relationship between the $17^{\text {th }}$ century sibling painters, Michaelina (Mons, 1604-Brussels, 1689) and Charles Wautier (Mons, 1609-Brussels, 1703), and the three eldest children of Charles I of England, in the context of the imminent restoration of the sovereignty of the Stuarts in Great Britain, whilst they were in Brussels during their exile. Together with the known Portrait of James, Duke of York (London, 1633-1701) by Charles Wautier, an anonymous portrait of a lady in red is subject to investigation, and identified as that of Mary Henrietta Stuart, Princess Royal of England, and Princess of Orange (London, 1631-1660). The princess would have sat for Charles' sister Michaelina in
\end{abstract}

1 (ㄱ) http://orcid.org/0000-000I-8564-9703 
early 1660 , at a moment when it is possible to locate her to Brussels, months before her untimely death. This significant new finding reinforces the Wautiers' relationship with the Stuarts whilst they were in exile, and further invites us to consider a portrait of the Stuarts older brother and soon-to-be King, Charles II (London, 1630-1685), conceived of under similar circumstances.

Keywords: Portrait; 17th Century; Netherlandish Painting; Brussels; Wautier; Female painter; Van Dyck; Stuart; Orange; Charles II; Stuart Restoration.

\section{Introducción}

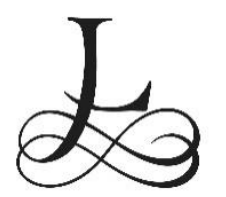

a producción retratística de los hermanos Michaelina (Mons, 1604-Bruselas, 1689) y Charles Wautier (Mons, 1609Bruselas, 1703) sabemos que fue grande en su tiempo. Desde la exposición dedicada a Michaelina en el verano de 2018 en Amberes $^{2}$, se continúa avanzando en el conocimiento de la producción de esta fascinante mujer pintora y de su hermano Charles. Sin embargo, su producción no es aún lo suficientemente conocida y sigue en construcción. Existe todo un espacio donde estos dos hermanos cohabitan no sólo física sino también artísticamente. Los dos permanecieron solteros, compartiendo vivienda y taller en Bruselas y sobran pruebas de que la unión entre ambos era vital. Al morir Michaelina en 1689, Charles es su heredero universal y éste a su vez, la menciona constantemente en sus testamentos ${ }^{3}$. Gozaban de una buena situación, adquiriendo conjuntamente varias propiedades, "a través del trabajo y los ingresos" -como bien especifica un documento ${ }^{4}$-. Tal compenetración explica el porqué al cotejar las escasas obras firmadas por uno y otro se observa que tienen un lenguaje artístico común y comparten el mismo estilo. La imbricación entre sus estilos dificulta deslindar su producción, tanto más si pensamos que en ocasiones debieron trabajar mano a mano, colaborando particularmente en los grandes formatos. No obstante, como se ha apuntado y como veremos al comparar sus retratos, las obras de Michaelina denotan una mayor perfección. De otra parte, hoy sabemos que los Wautier tuvieron un taller activo, con ayudantes que reprodujeron sus obras con variable fortuna; prueba de ello son los numerosos ejemplares de la Vocación de San Mateo, una de sus composiciones más exitosas 5 .

\footnotetext{
2 Michaelina Wautier 1604-1689. Glorifying a Forgotten Talent, dir. Katlijne Van der Stighelen, (Anvers: Rubenshuis-MAS, 2018).

3 No se ha conservado el testamento de Michaelina Wautier, fechado el 17 de marzo de 1662, pero documentos posteriores confirman que Charles fue su heredero universal. "Jouffrouwe Michiele Wautier sijne sustere (van dewelcke hij universelen erffgenaem is)" [La señorita Michiele Wautier, su hermana (de la que es heredero universal)]. Bruselas, Archives Générales du Royaume (en adelante AGRB), Schepengriffe, Reg. 1405, $4^{\mathrm{e}}$ sextern, 20-06-1697; 62 ${ }^{\mathrm{e}}$ sextern, 21-04-1698. Cit. K. Van der Stighelen, "Growing up with Eight Brothers", en Michaelina Wautier 1604-1689, p. 29, nota 95.

4 Según consta en documento notarial de cesión de propiedad del 16 de septiembre de 1732. AGRB, Notario Guillaume van der Borcht, n 4527/3. Cit. Van der Stighelen, "Growing up", pp. 34-35.

5 A propósito de las numerosas versiones existentes con esta composición: Jahel Sanzsalazar, "La Vocación de San Mateo: ¿obra de Michaelina y Charles Wautier?", Tendencias del mercado del Arte, (mayo 2019), pp. 88-92.
} 


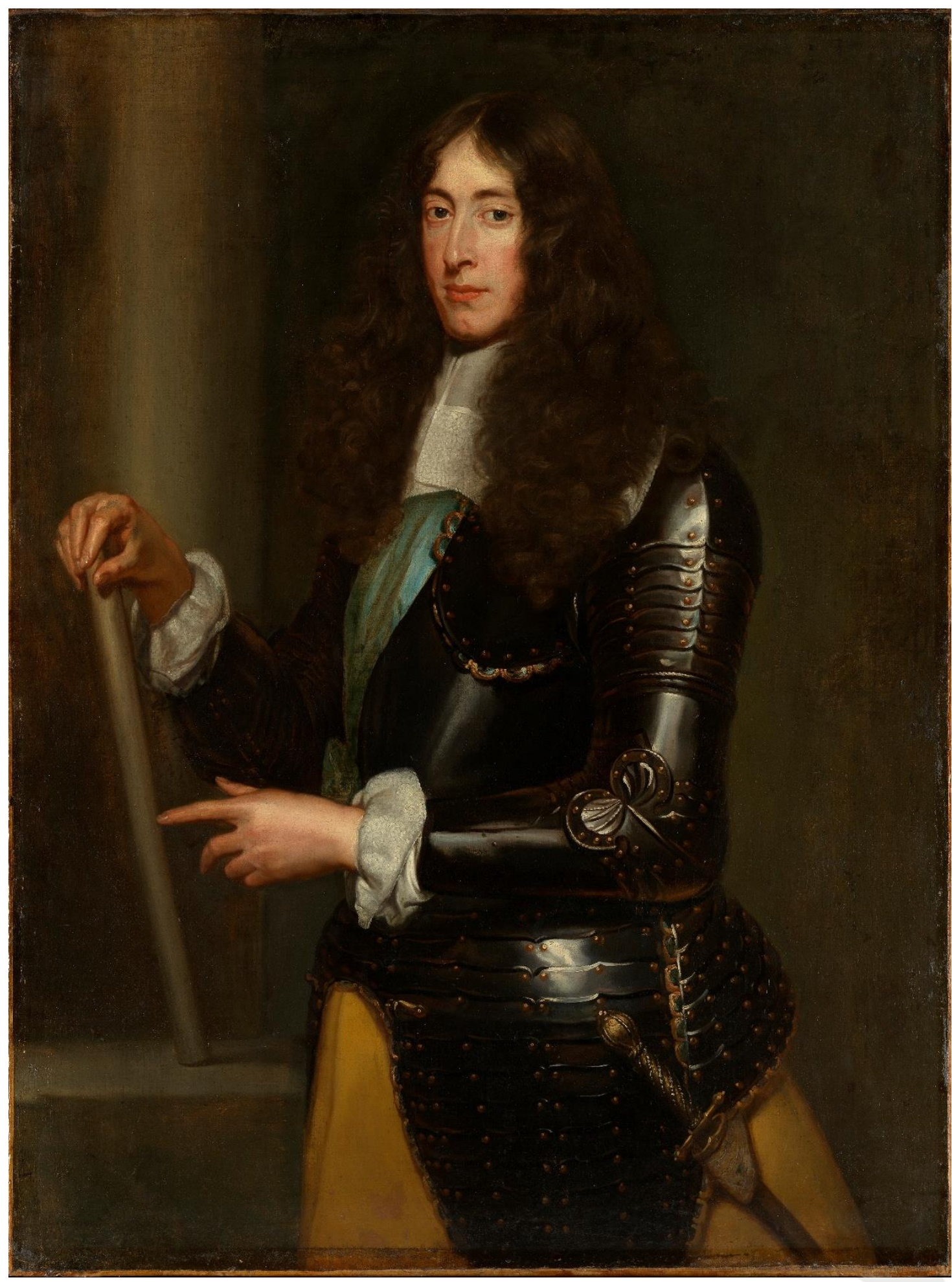

Fig. 1. Charles Wautier, Retrato de James Stuart, duque de York, ca. 1658-1660. (Lienzo, $124 \times 93$ cm.) Palacio de Holyroodhouse, () Royal Collection Trust (RCIN 402572) 
Parece claro que, a pesar de ser mujer, pintar no era para Michaelina Wautier un simple pasatiempo, como lo fue para otras damas de la alta sociedad. Sin embargo, es su hermano el que aparece inscrito en la guilda de pintores como tal, aunque tardíamente en el año 1651. Los documentos prueban que Charles estuvo ejerciendo la profesión de pintor durante años sin declararse: desde 1642 recibe sucesivas amonestaciones por parte de las autoridades, hasta el punto de que en 1643 se le prohíbe ejercer en Bruselas $^{6}$. En este lapso de tiempo no se conocen obras firmadas por Charles. Sin embargo, Michaelina firmó el Retrato de don Antonio Pimentel de Prado en $1646^{7}$ (Fig. 7), los Desposorios de Santa Catalina en $1649^{8}$, y una serie con los Cinco Sentidos en 1650 que aún está por aparecer. En lo sucesivo es el nombre de Charles Wautier el que se lee en los documentos de la guilda de pintores de Bruselas: desde 1653 hasta 1686 figura como maestro de diversos alumnos ${ }^{9}$.

Su fama debió crecer particularmente por su pericia en el arte del retrato, que es lo que se alaba en los versos que le dedica en 1658 el pintor Florent du Rieu: "A Charles Wautier, pintor de retratos de la ciudad de Bruselas: Wautier en el arte de la Pintura / Hace mucho más que la Natura Pues comparada a sus trazos / apuesta por sus Retratos"10. Ciertamente la calidad de los retratos hasta hoy localizados ilustra con contundencia las alabanzas del poema. Ignoramos porqué se omite el nombre de Michaelina, pues los retratos firmados por ella lo merecen con igual o mayor derecho. El

${ }^{6}$ K. Van der Stighelen, "Prima inter pares: Over de voorkeur van Aartshertog Leopold-Wilhelm voor Michaelina Woutiers (ca 1620-na 1682)", en Sponsors of the past: Flemish art and patronage 15501700, Symposium Katholieke Universiteit Leuven, (14-15 December 2001), (Turnhout: Brepols, 2005) pp. $108-109$.

7 (Lienzo, 63 x 56,5 cm). Firmado y fechado arriba a la derecha: "Michaelina Wautier 1646". Bruselas, Musées Royaux des Beaux Arts, (inv. no 297). Adquirido en 1812 a M. Thys. H. Fierens-Gevaert, Musées Royaux des Beaux-Arts de Belgique. Catalogue de la peinture ancienne, (Bruxelles, 1922), p. 232, no 934; H. Fierens-Gevaert y A. Laes, Musées Royaux des Beaux-Arts de Belgique, 2a ed., (Bruxelles, 1927), pp. 37, 238, 294; J. Sanzsalazar, "Michaelina Wautier y el enviado español", Tendencias del mercado del Arte, (abril, 2018), pp. 88-91, identifica el retrato como Retrato de Don Antonio Pimentel de Prado. Van der Stighelen lo cita como Retrato de un mando del ejército español en 2018. K. Van der Stighelen, "Portrait of a Commander in the Spanish Army", en Michaelina Wautier 1604-1689, pp. 162165, cat. 2. Sobre los grabados de este personaje según Charles Wautier: Sanzsalazar, "Michaelina Wautier y el enviado", p. 89; Pierre-Yves Kairis, "Various engravers after Charles Wautier", en Michaelina Wautier 1604-1689, p. 268, cat. 29.

8 (Lienzo, $157 \times 218 \mathrm{~cm}$ ). Firmado y fechado abajo a la izquierda: "Michaelina Wautier invenit et fecit 1649". Namur, Seminario diocesano. Pierre-Yves Kairis, "Le portrait dans le Namurois au XVIIe siècle, en Portraits en Namurois, ed. Jacques Toussaint, (Namur: Société archéologique de Namur, 2002), pp. 4041; K. Van der Stighelen, "The Mystic Marriage of Saint Catherine", en Michaelina Wautier 1604-1689, pp. 200-203, cat. 10. La pintura fue restaurada en el Instituto Real de Patrimonio Artístico de Bruselas (KIK-IRPA) a cargo de Karen Boone en vistas de la exposición. Nuestro agradecimiento a Pierre-Yves Kairis que gentilmente nos hizo llegar copia del informe de restauración con valiosas observaciones (comunicación escrita con la autora: 28-08-2020).

${ }_{9}$ AGRB, T082, n 818, 203, 214, 226, 231, 232, 264, 271. cit. Van der Stighelen, "Growing up", p. 22. 10 "Wautier dans I'art de la Peinture/ Fait beaucoup plus que la Nature, Puis que comparee à ses traits / elle prise pour ses Portraits". Florent du Rieu, Les tableaux parlans du peintre Namurois, (Namur: chez Pierre Gerard, 1658), conjunto de poesías dedicadas por el autor a los principales artistas flamencos. PY. Kairis, "Foisonnement et diversité: les peintres du XVIIe siècle", en Un double regard sur 2000 ans d'art wallon, coord. Liliane Sabatini y Martine Ferrante-Hollenfeltz, (Liège: Musée de l'Art Wallon; Tournai: Belgique: Renaissance du Livre, 2000), p. 338; J. Sanzsalazar, "The influence of Others. The Wautiers, David Teniers and the Archduke Leopold Wilhelm's Theatrum Pictorium", en Michaelina Wautier 1604-1689, p. 73. 
hecho de que Charles Wautier fuera solicitado en 1662, junto a cinco de los pintores más relevantes del momento, para valorar una pintura de Pieter Snayers (Amberes, 1592-1667), testimonia su alta consideración ${ }^{11}$. Sin embargo, es el nombre de ella y no el de él el que aparece citado tres veces en 1659, en el inventario de pinturas de la ilustrísima colección del archiduque Leopoldo Guillermo de Austria (Wiener Neustadt, 1614-Viena, 1662), lo que es prueba muy fehaciente de un reconocimiento real, aunque olvidado por la historiografía hasta fechas recientes ${ }^{12}$. No obstante, fue Charles Wautier quien ejecutó el imponente Retrato del archiduque Leopoldo Guillermo vencedor de la Batalla de Dunkerque (1653) localizado recientemente en un castillo de Bohemia ${ }^{13}$.

\section{El Retrato de James Stuart, duque de York}

Impresiona, en efecto, la importancia de los personajes retratados por los Wautier, pues inmortalizaron tanto a militares de los más altos rangos como a brillantes intelectuales, miembros del clero, nobles y príncipes. Entre ellos destacaremos el Retrato de James Stuart, duque de York de la Royal Collection por ser elemento crucial en nuestra argumentación ${ }^{14}$. (Fig. 1) Esta pintura se atribuye a Charles Wautier en base a la inscripción " $\mathrm{C}$. Woutier pinxit" de dos grabados que ejecutan Peter de Jode $\mathrm{II}^{15}$ y Theodoor van Merlen ${ }^{16}$, quienes lo reprodujeron de busto, obviando la armadura y el bastón de mando, alusiones a las campañas militares del príncipe británico durante su más larga estancia en los Países-Bajos españoles. Son varias las ocasiones en las que el duque de York (Londres, 1633-1701), hijo de Carlos I de Inglaterra (Rosyth, 1600-Londres, 1649), estuvo en Bruselas. Primeramente, en 1648, cuando camino de Francia el archiduque Leopoldo

\footnotetext{
11 Junto a "C. Wautier" firman el documento Gaspar de Crayer, David Teniers, Louis Primo "il Gentile" y Daniel van Heil. Valenciennes, Archivo municipal, documento publicado por P. Foucart y M. Henault, "Une toile de Pierre Snayers", Réunions des Sociétés des Beaux-Arts et des Départements en 1895, (Paris, 1895), pp. 308, 333, pl. viii; Van der Stighelen, "Growing up", p. 30, fig. 16; Sanzsalazar, "The influence of Others", p. 73, nota 32.

12 Sanzsalazar, "The influence of Others", pp. 67-83.

13 (Lienzo, $210 \times 120 \mathrm{~cm}$ ). Supuestamente firmado por Charles Wautier. Bohemia del Sur, República Checa, Castillo de Hluboká nad Vltavou, (inv. HL-HL-05510). Sanzsalazar, "The influence of Others", pp. 70-72; J. Sanzsalazar, "Encarar el miedo: Don Francisco Fernández de la Cueva, VIII duque de Alburquerque (1619-1676), Virrey de Nueva España y de Sicilia; sobre su estancia en Flandes y su retrato por los hermanos Michaelina y Charles Wautier", Philostrato. Revista de Historia y Arte, $\mathrm{n}^{\circ} 7$, (2020), pp. 67-70, nota 15 y fig. 6.

${ }_{14}$ (Lienzo, $124 \times 93 \mathrm{~cm}$ ). Palacio de Holyroodhouse, Royal Collection Trust (RCIN 402572). Adquirido por la reina de Inglaterra en 1960 a D. Baskett de Colnaghi. Oliver Millar, The Tudor, Stuart and Early Georgian Pictures in the Collection of Her Majesty the Queen, (London, 1963), p. 215, y fig. 92, atribuido a Charles Wautier; O. Millar, Later Georgian Pictures in the Collection of Her Majesty the Queen, (London, 1969); Sanzsalazar, "The influence of Others", p. 71; K. van der Stighelen, "Michaelina's Versatile Hand. A career without Beginning or End?", en Michaelina Wautier 1604-1689, p. 148.

${ }^{15}$ Grabado con la inscripción: "C. Woutier pinxit/ P. de Iode Sculp/ Ioan. Meÿssens exc. Antverpiæ"; y la leyenda: "IAQUES DUC DE IORK II / Fils de ChARLES I. Roÿ d'Angleterre Irland etc.". Véase el ejemplar de la National Portrait Gallery de Londres, (inv. NPG D18568).

${ }^{16}$ Con la inscripción "C. Woutier pinxit. / Th Van Merlen exc. Antverpiæ"; y la leyenda: "IAQUES DUC DE IORK II ${ }^{\mathrm{e}}$ / Fils de CHARLES I. Roÿ d'Angleterre Irland etc.". Ámsterdam, Rijksmuseum, Rijksprentenkabinet, (RP-P-OB-23.552). Millar, The Tudor, Stuart, p. 116; Kairis, "Various engravers", no cat. 32.
} 


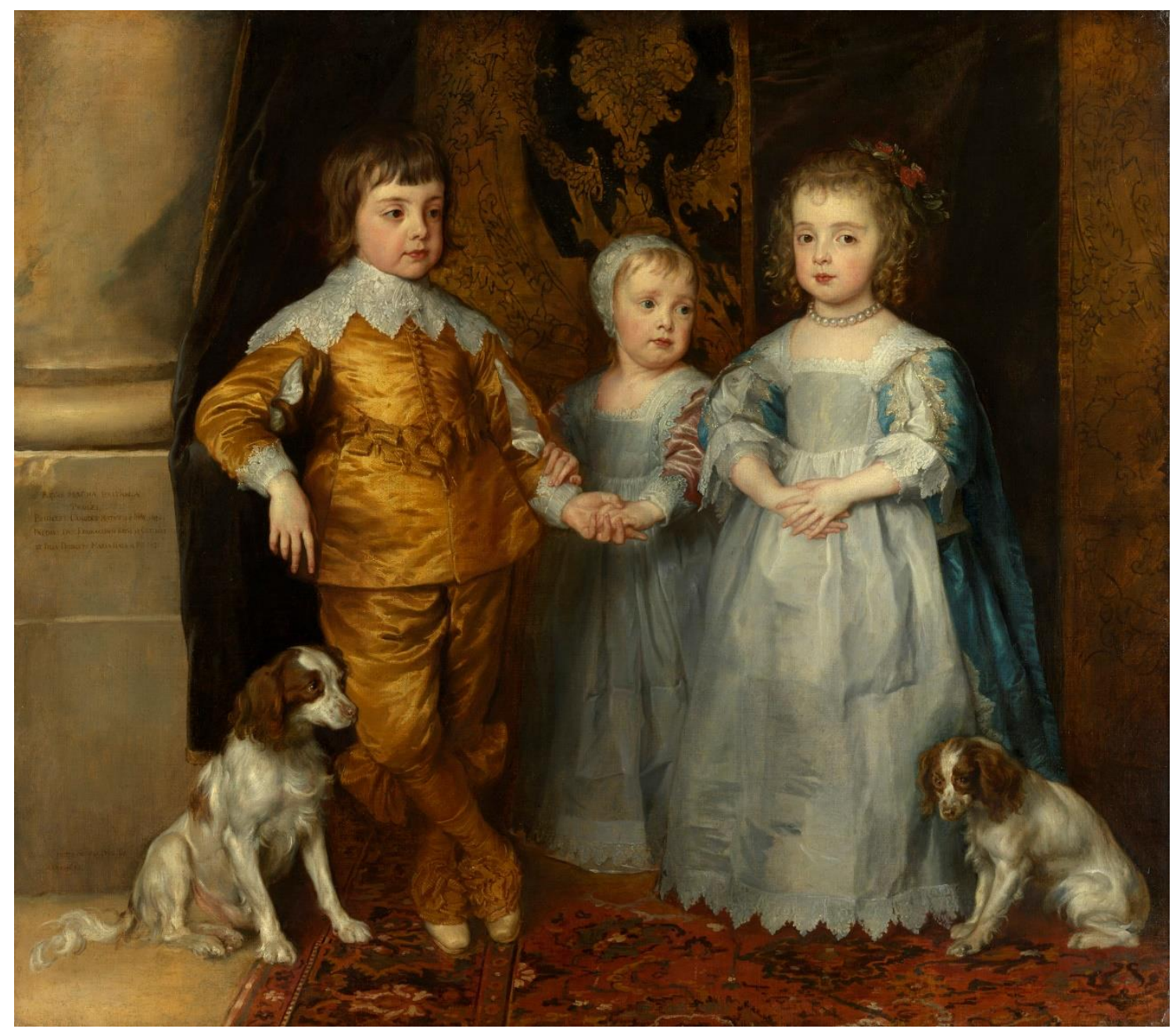

Fig. 2. Anton van Dyck, Retrato de los tres hijos mayores de Carlos I, 1635. (Lienzo, 133,4 x 151,8 cm.) Londres, () The Royal Collection (RCIN 404403)

Guillermo le ofrece refugio en la abadía benedictina de Cambrai ${ }^{17}$. Volvió a finales de 1650 y se quedó varios meses antes de su regreso a La Haya en $1651^{18}$. Por último, en 1657 fijó residencia en Brujas junto a su hermano, el futuro Carlos II (Londres, 1630-1685), ofreciendo sus servicios al ejército español ${ }^{19}$. Fue entonces nombrado capitán general de la armada del Océano, recibiendo el mando del ejército en Dunkerque, y destacando por su heroica conducta en la batalla de las Dunas el 14 de junio de $1658^{20}$.

Lo más probable es que el retrato, con evidente exaltación de su imagen militar, conmemore este hecho y date del mismo año; siendo indudable-

\footnotetext{
${ }_{17}$ Francis Charles Turner, James II, (London: Eyre \& Spottiswoode, 1948 y 1950), p. 22.

18 Memoirs of James the Second, king of England, \&c. \&c.; collected from various authentic sources, (London 1821), vol. I, pp. 53, 64-66.

${ }_{19}$ Carlos II vivió oficialmente en Brujas desde el 22 de abril de 1656 al 15 de marzo de 1659 . Varios lienzos conmemoran la recepción de Carlos II y sus hermanos en la Schuttershof y en la guilda de Santa Bárbara realizados por Jan Baptist van Meunincxhove en 1671, (lienzos, 249 x 199 cm.) Brujas, Groeningemuseum, (inv. no GRO1377.I y 1378.I); así como en la guilda de San Joris (Lienzo, 83 x 141,5 cm.), obra firmada y fechada por "Eug.Legendre" en 1886. (Cliché KIK-IRPA: B075206).

20 James Inglis-Jones, "The Battle of the Dunes, 1658: Condé, War and Power Politics", War in History, vol. $1, n^{\circ} 3$ (Nov. 1994), pp. 249-277.
} 
Fig. 3. Anton van Dyck, Retrato de Willem II, príncipe de Orange, y Marry Henrietta Stuart, hija de Carlos I de Inglaterra, 1641. (Lienzo, $180 \quad \mathrm{x} \quad 132,2 \mathrm{~cm}$.) Ámsterdam, (C) Rijksmuseum (inv. SK-A-102)

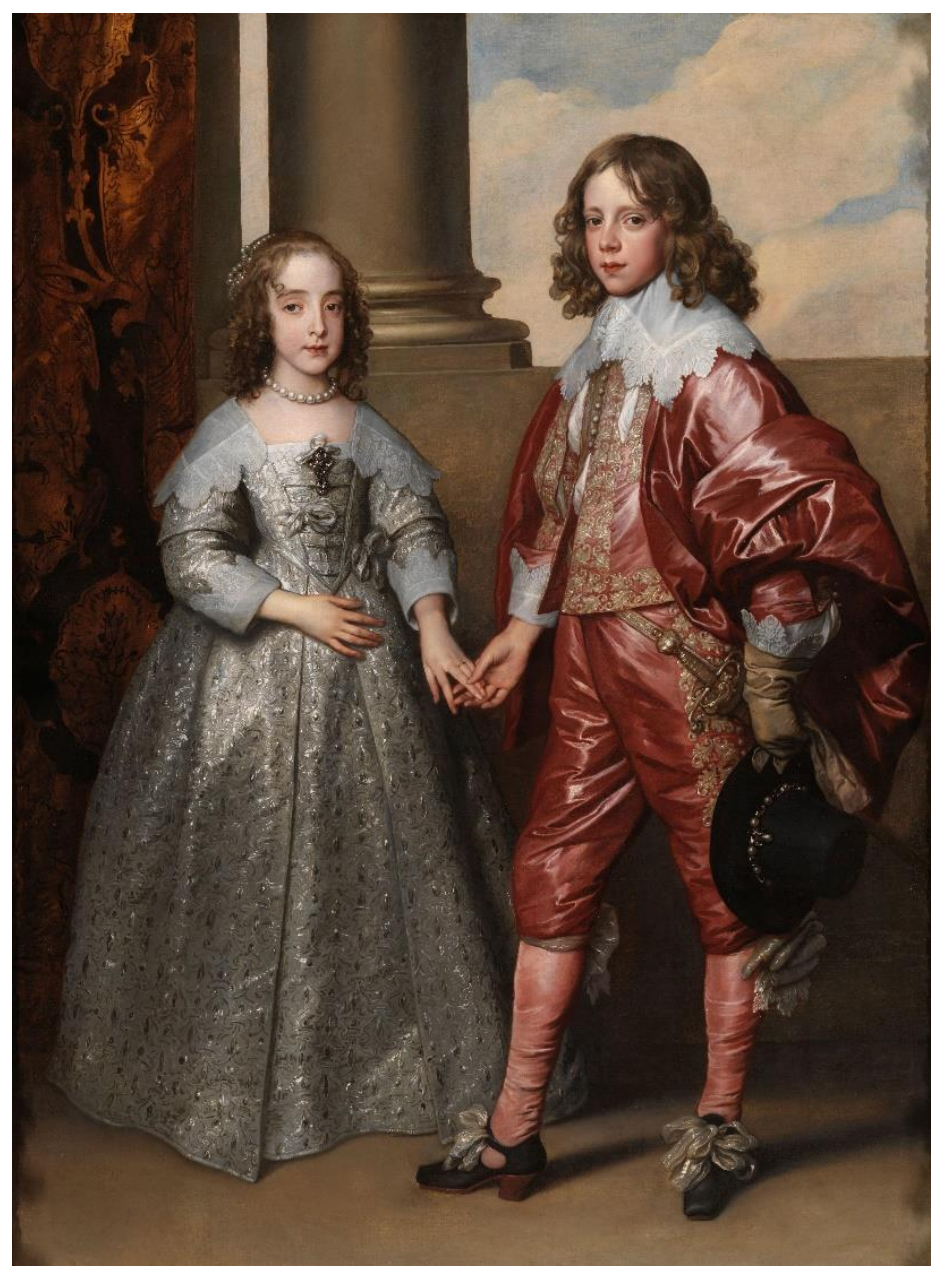

mente anterior a 1660, final del exilio del duque y fecha de la Restauración de la monarquía británica. Por entonces, la fama de Charles Wautier como retratista era grande. La fórmula utilizada es comparable a la del citado Retrato del archiduque Leopoldo Guillermo vencedor de la Batalla de Dunkerque (1653). El duque de York tendría unos veinticinco años; está retratado de tres cuartos, apoyando el bastón de mando en un plinto, vestido con media armadura de caballería y luciendo en el pecho la insignia de la orden británica de la Jarretera. Testimonios contemporáneos nos hablan de su gran valentía ${ }^{21}$, y de la envidia que suscitó en Don Juan José de Austria (Madrid, 1629-1679) por la fuerza con la que conducía a sus tropas $^{22}$. Dado el largo tiempo que pasó en Bruselas, no sería imposible que posara para los Wautier en más de una ocasión. A este respecto nos

21 "The Duke of York will take exceedingly in the army; he is brave, and as little troublesome as any Prince can be". John Thurloe, A Collection of the State Papers of John Thurloe, Secretary First to the Council of State. Containing Authentic Memorials of the English affairs from the year 1638 to the Restoration of King Charles II., (London: for the executor of F. Gyles, 1742), VI, pp. 326, 338, 343, 363; Eva Scott, The travels of the King Charles II in Germany and Flanders, 1654-1660, (London: Archibald Company, 1907), p. 301.

22 Scott, The travels, 1907, p. 302. 
interpela - sin poder darle mayor crédito- la entrada de un catálogo de venta de 1969, que describe: "Wautier. Retrato dicho de James II, sentado, de cuerpo entero, un libro sobre la mesa a su derecha"23.

No se sospechaba aún que James, duque de York, ocuparía el trono de Inglaterra años después (1685-1688), al morir su hermano Carlos II sin descendencia legítima. Largo deambular por Europa tuvieron los príncipes de Estuardo al ser decapitado su padre, Carlos I de Inglaterra, en 1649. iCuánto les acontecería desde que posaran para Anton van Dyck (Amberes, 1599-Londres, 1641) siendo tan niños! Recordamos aquel retrato, tantas veces copiado, en el que están juntos los tres mayores; James con poco más de dos años, dando la manita a su hermano Carlos, el primogénito y heredero, en compañía de la princesa Mary Henrietta y de dos spaniels ${ }^{24}$. (Fig. 2) La vida de los tres iba a estar unida en el exilio; en desesperada búsqueda de apoyos financieros y militares para la causa realista, con idas y venidas entre Holanda, Francia, Alemania y los Países Bajos españoles, hasta la Restauración de la monarquía británica en 1660.

A Mary Henrietta Stuart (Londres, 1631-1660) la habían prometido a la edad de ocho años con el príncipe Willem II de Orange (La Haya, 16261650) y partiría al poco para La Haya. Muy impactante es el bellísimo retrato que Van Dyck hizo en 1641 de los jovencísimos novios ${ }^{25}$. (Fig. 3) Cuando James, duque de York, fue hecho prisionero durante la guerra que opuso a Carlos I con el parlamento británico, escapó y buscó refugio junto a su hermana. La caída de su padre era inminente. La reina Henrietta Maria (Paris, 1609-Colombes, 1669) había dejado Inglaterra desde el verano de 1644, para refugiarse en el palacio del Louvre que la vio nacer. Acababa de morir su hermano, el rey Louis XIII de Francia (Fontainebleau, 1601-SaintGermain-en-Laye, 1643), y el futuro Louis XIV (Saint-Germain-en-Laye, 1638-Versalles, 1715) tenía tan sólo cuatro años. Francia estaba bajo la regencia de Ana de Austria (Valladolid, 1601-Paris, 1666) y el control del cardenal Mazarino (Pescina, 1602-Vincennes, 1661). Tanto Carlos como James, pasarían un tiempo junto a su madre en París, partiendo a mediados de julio de 1648 para reunirse con su hermana en La Haya, donde se les ofrecía pensión y palacio. Al enterarse de la decapitación del padre, Carlos II acudió a Escocia, donde fue reconocido como rey de los escoceses pero, al cabo de quince meses, derrotado y humillado, volvió a París en octubre de 1651. Al empezar Mazarino a tratar con Oliver Cromwell (Huntingdon, 1599-Londres, 1658) en 1654, Carlos II se ve obligado a dejar Francia. Marcha entonces para Colonia y Fráncfort del Meno pero, cuando la Inglate-

\footnotetext{
23 "Wautier. Portrait said to be of James II, seated, full length, a book on the table to his right. $771 / 2 \times$ $461 / 2$ in, $197 \times 118 \mathrm{~cm}$, canvas". Londres, Sotheby's, venta A.G. Hickman y otros, (30-VI-1969, no lot. $38)$.

24 (Lienzo, 133,4 x 151,8 cm). Firmado y fechado en 1635. Londres, The Royal Collection (inv. no RCIN 404403). Susan Barnes, Nora de Poorter, Oliver Millar y Horst Vey, Van Dyck. A Complete Catalogue of the Paintings, (London-New Haven: Yale University Press, 2004), p. 479, cat. IV.61.

25 (Lienzo, 180 x 132,2 cm). Ámsterdam, Rijksmuseum (inv. no SK-A-102). Barnes et al., Van Dyck, p. 616 , cat. IV.242.
} 


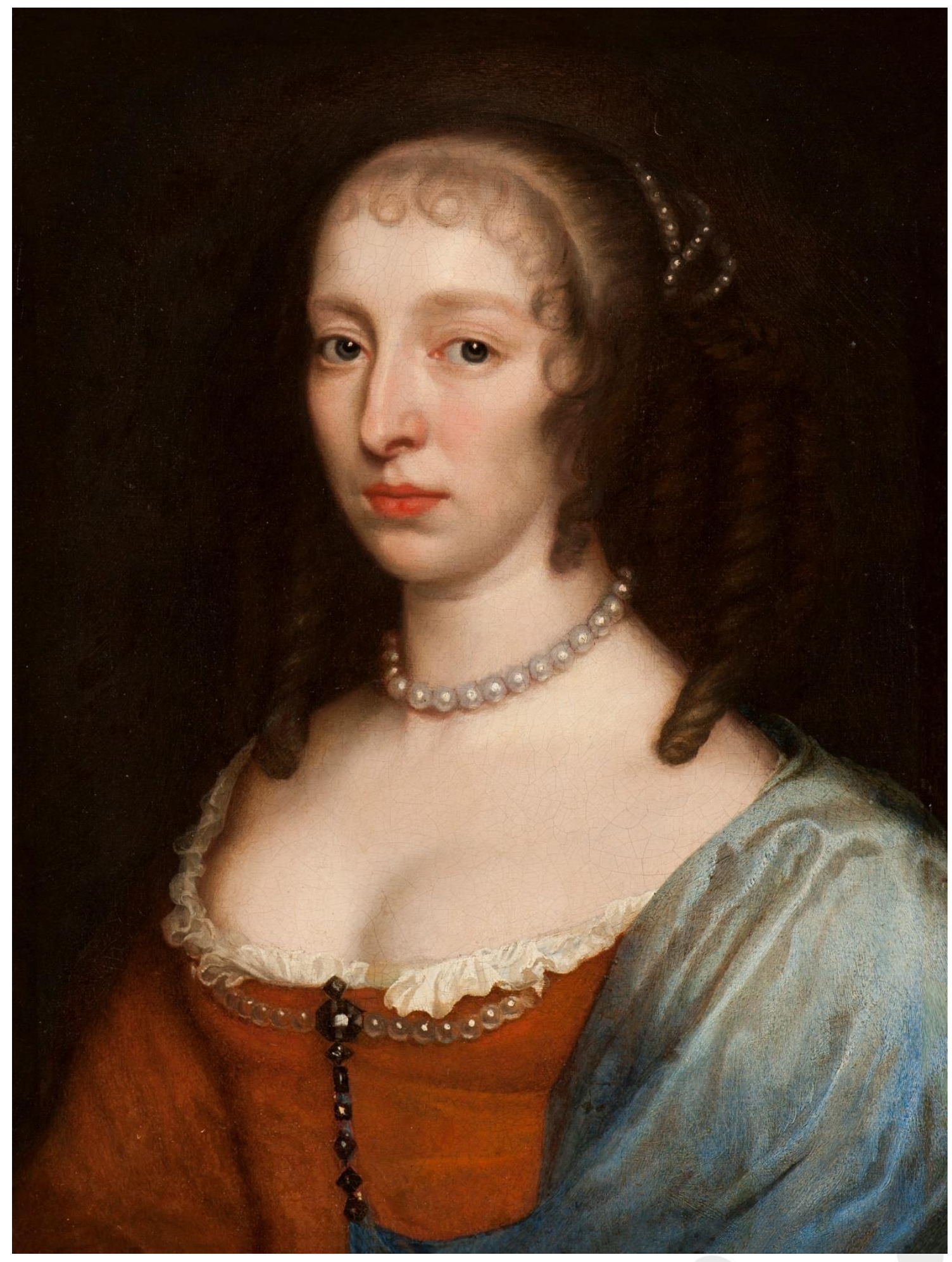

Fig. 4. Atribuido aquí a Michaelina Wautier, Identificado como Retrato de Mary Henrietta Stuart, Princesa Real y Princesa de Orange, ca. 1660. (Lienzo, 61,5 x 46,5 cm.) Madrid, colección particular. (C) Foto autora 
rra de Cromwell entra en guerra con España, ve la posibilidad de buscar el apoyo español, por lo que se instala en los Países-Bajos españoles. A su vez James abandona el ejército francés y empieza a luchar junto al bando español.

\section{El Retrato de Mary Henrietta Stuart}

Lo cierto es que Bruselas fue un punto de encuentro de los tres hijos mayores de Carlos I en el exilio. En este contexto en el que el duque de York acude a los Wautier para fijar su retrato, con el que quedaría satisfecho pudo ser el motivo para recomendar a su hermana, Mary Henrietta, princesa real y princesa de Orange, que se hiciera retratar por ellos. Pensamos se trataría del Retrato de dama vestida de rojo (Lienzo, $61,5 \times 46,5 \mathrm{~cm}$ ), hasta hoy sin identificar al personaje y sin reconocer al autor, y que aquí relacionamos con Mary Henrietta y con los pinceles de Michaelina. (Fig. 4)

En 1985, Didier Bodart asociaba este retrato con Peter Lely (Soest, 1618Londres, 1680), identificando a la retratada con Mary II Stuart (Londres, 1662-1694) ${ }^{26}$. Por entonces, la producción de los Wautier era prácticamente desconocida; pero la aproximación del profesor belga - que debió reconocer la ascendencia vandyckiana en el retrato- no deja de apuntar influencias que corresponden con los Wautier y a un personaje de la familia Estuardo. El estilo de Peter Lely es, no obstante, más ampuloso; domina en sus retratos el lujo de las telas y una sensual languidez, con una iluminación más dramática y una ejecución más dura que no se ven aquí. Por cronología, tampoco puede tratarse de Mary II Stuart. La moda y el peinado ayudan a situar el retrato en el tiempo y descartan esta identificación. La joven lleva el peinado llamado "a la garceta", que consistía en el cabello tirante y recogido en un moño en la coronilla con bucles cayendo sobre los hombros y caracolillos rodeando la frente. Estuvo de moda durante varias décadas desde los años 1630, siendo remplazado por el peinado "a la hurluberlu", hacia los años 1665-1670, distinto al anterior por llevar raya al centro, el cabello con gran volumen de bucles agrupado a ambos lados y dos tirabuzones largos cayendo sobre los hombros. Por tanto, esta moda en el tocado fija una cronología entre 1630 y 1665 . No obstante, es el ropaje el que ayuda a precisar mejor su periodo de ejecución. La joven viste un traje encorsetado de terciopelo rojo de escote ovalado hasta los hombros y el nacimiento del pecho, sobrepasando un ribeteado fruncido de muselina blanca, exquisitamente observado en su discontinua alineación. Cubre el hombro izquierdo con un manto azul asido a la pechera por una cadena de

${ }^{26}$ Se informa de la existencia de una carta de tres páginas manuscritas del profesor Didier Bodart (5-031985) a la cual no hemos tenido acceso, en la que identifica a la retratada con Mary II Stuart (16621694 ) y sugiere a Peter Lely como autor. París, Rossini Maison de ventes aux encheves, marzo 2020, $\mathrm{n}^{\circ}$ 68: "Portrait d'une femme en buste, attribué à Peter Lely". 
Fig. 5. Charles Wautier, Retrato de dama vestida de azul, 1660. (Lienzo, $117 \mathrm{x}$ $86 \mathrm{~cm}$.) Paradero actual desconocido. (C) Foto autora

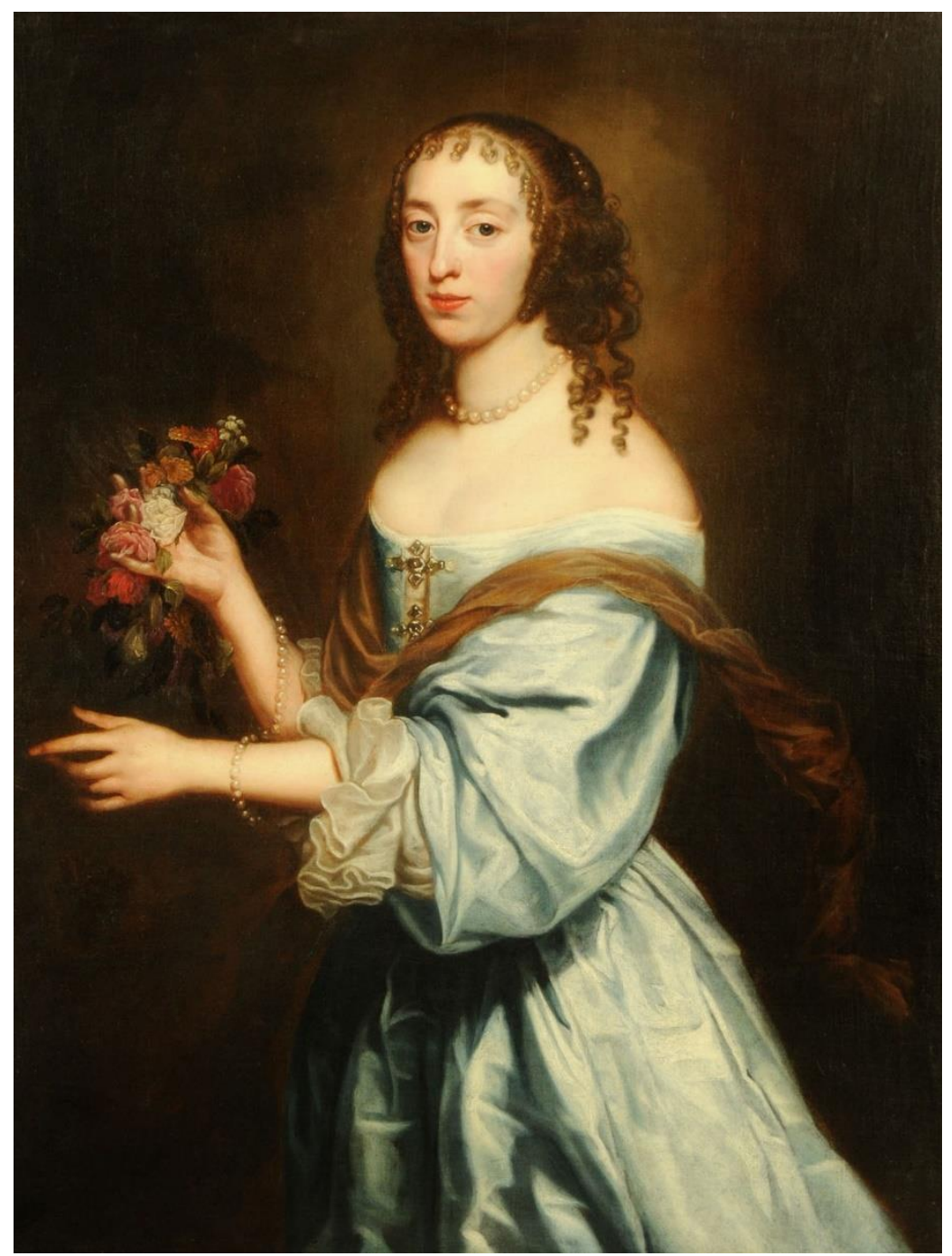

piedras negras. Este tipo de vestido se usa entre 1660 y $1670^{27}$, lo que nos permite, junto con la moda del peinado, acotar la fecha del retrato a los años de 1660-1665.

Lo primero que llamó nuestra atención fueron las numerosas evidencias formales y estilísticas que resultan al comparar este retrato con otros conocidos en la producción de los Wautier. Las semejanzas con el Retrato de James, duque de York son notables. (Fig. 1) Ambos presentan el mismo encaje del rostro y análogo diseño de la nariz, de los ojos y de los labios. Muy llamativa es también la comparación con un Retrato de dama vestida de azul que salió a la luz hace poco, con la firma de Charles Wautier y la fecha de $1660^{28}$. (Fig. 5) Al cotejarlo con este retrato en estudio, observa-

\footnotetext{
27 Véase, por ejemplo, un Retrato de dama por Jan van Haensbergen (Tabla, $28,5 \times 21,5 \mathrm{~cm}$.), firmado: "J.v.H.f.", en colección privada; o el Retrato de Jacoba van Liere por Pieter Nason (lienzo, 87 x 68,5cm), firmado y fechado en 1671, en el palacio de Duivenvoorde en Voorschoten (Zuid Holland).

28 (Lienzo, 117 x $86 \mathrm{~cm}$.), firmado y fechado: "C. WAUTIER/ FECIT. 1660", actualmente en paradero desconocido. Anteriormente en: Julian Simon Fine Art, Pimlico Rd, Londres (31-01-1992), colección privada; Cockermouth, Cumbria UK Mitchells auctions, (9-06-2016, lot. no 769); Londres, Titan Fine Art.
} 


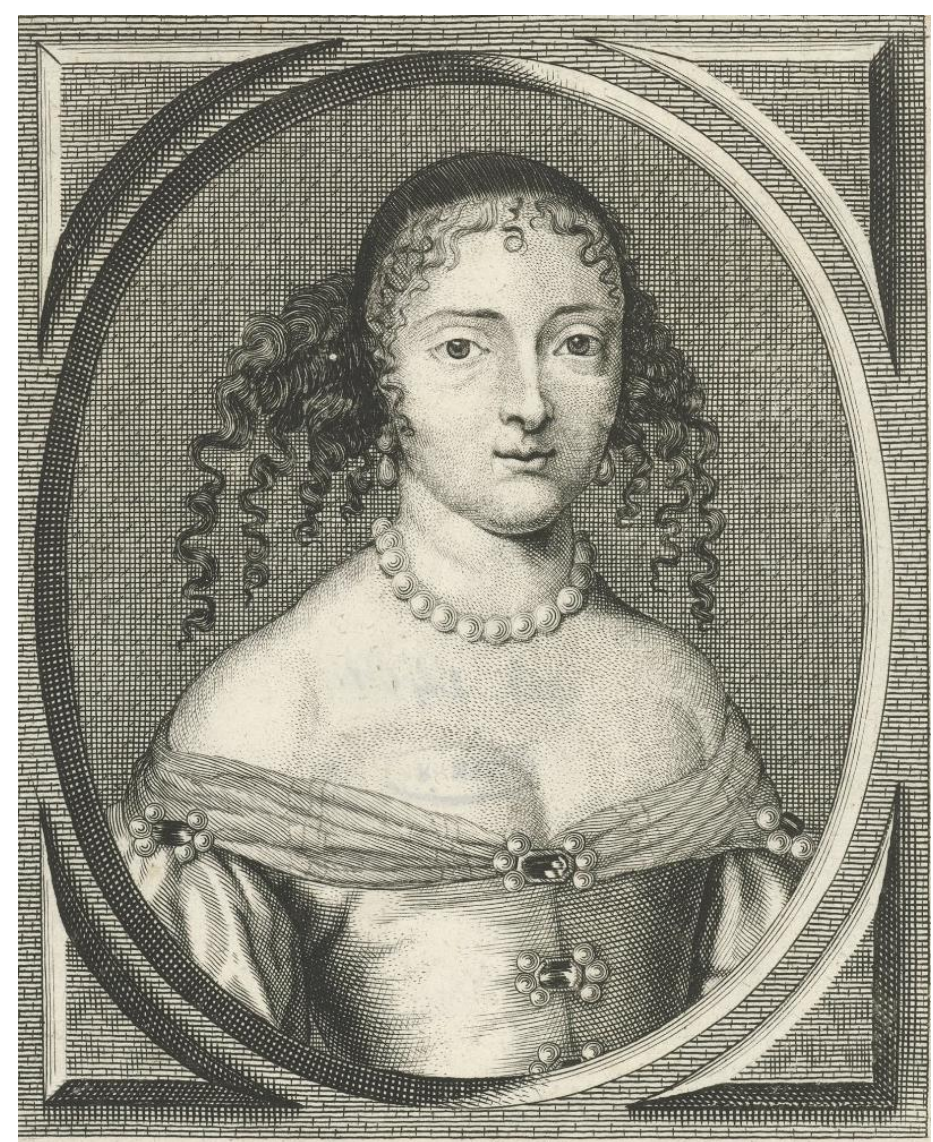

FLORENS MARGVERTte de Reneße Comtefe de Grimberghe etc.

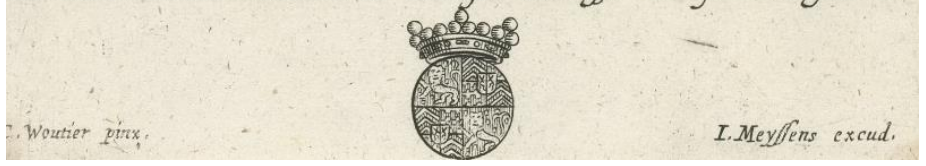

Fig. 6. Cornelis Meyssens siguiendo a Charles Wautier, Retrato de Florentine Margarethe van Renesse van Elderen, Condesa de Grimbergen, ca. 1660. Grabado. Ámsterdam, () Rijksmuseum, (RP-P1908-2481)

mos que -al margen de las similitudes en el peinado y las joyas- hay correspondencias en la posición de la cabeza y en la composición del rostro, con análogo diseño de la nariz, los labios y las cejas. También es comparable con el Retrato de la Condesa de Grimbergen, Florentine Margarethe van Renesse van Elderen (Lieja?, ca. 1620 - 1665), conocido por un grabado con la inscripción "C. Woutier pinx" 29. (Fig. 6) La figura tomada de busto, dibujando una misma línea del escote y los hombros, demuestra la utilización de esquemas análogos. Ambas damas llevan un collar de perlas y el pelo recogido del mismo modo. El rostro de la condesa

\footnotetext{
${ }^{29}$ El grabado contiene la inscripción: "FLORENS MARGVERITE de Renesse comtesse de Grimberghe etc..." y, debajo: "C. Woutier pinx."; el escudo de armas, y "I. Meyssens excud.". Ámsterdam, Rijksmuseum (n.o inv. RP-P-1908-2481). Hace pareja con un retrato de su esposo, Eugene de Berghes $(\dot{i}-1670)$, conde de Grimberghe y barón de Arquennes, con quien la joven casó en 1641. Véase su retrato grabado con la inscripción: "EVGENE de Berghes de Grimberghe etc..."; "C. Woutier pinx.", y "I. Meÿssens excud.". Londres, British Museum, (no inv. 1869, 0612.16). (En web: https://www.britishmuseum.org/collection/object/P 1869-0612-16, consultada: 7 de diciembre de 2020); Kairis, "Various engravers", cat. 30. Véase también su retrato al óleo del castillo de Beloeil (lienzo, 111 × 89 cm.; Cliché KIK-IRPA B189995) advertido en sucesivas ocasiones: Sanzsalazar, "The influence of Others", p. 82, nota $30, n^{\circ} 2$.
} 
se presenta más frontal, mientras que el de nuestra dama está girado de tres cuartos volviendo la mirada al espectador.

Pese a estas analogías formales con los retratos apuntados de Charles Wautier, el Retrato de Mary Henrietta Stuart se debe, a nuestro parecer, a Michaelina. Si bien el estilo de los Wautier es muy afín, hay sutiles diferencias entre ambos que se detectan mediante una observación muy detenida. No vemos, en los retratos de Michaelina la tendencia a la alargada estilización, algo excesiva, que observamos en los ejecutados por su hermano. Esto es patente tanto en el Retrato del archiduque Leopoldo Guillermo como en el de James, duque de York, como en el Retrato de dama vestida de azul, anteriormente citados, donde cabe apuntar además pequeñas incorreciones en las que Michaelina no cae. El brazo izquierdo de ésta, por ejemplo, resulta demasiado largo y descompensado. Los pliegues del vestido están cargados de sombras excesivamente duras. Faltan, en cambio, las sombras que modelan el busto para restituir su natural redondez, matiz perfectamente plasmado en el retrato que estudiamos. Obsérvense otras diferencias en la línea de los hombros y en el modelado de las carnaciones. Los retratos de Michaelina se caracterizan por una mayor perfección y equilibrio, resultando impecables en su encaje y ejecución. Otro matiz a considerar es la característica manera de pintar las perlas, idéntica a la que se ha apuntado en los Desposorios de Santa Catalina del Seminario de Namur, pintura firmada y fechada en 1649 por Michaelina y que ha sido recientemente objeto de una cuidada restauración ${ }^{30}$. En el retrato en estudio se observa la misma economía de materia, el uso de tonos grises, el toque de luz en el lugar correcto para modelar el círculo, y la utilización del color subyacente, en este caso el rojo del vestido, el ocre de la piel y el negro de los cabellos, para plasmar su transparencia. Esto es distinto en el Retrato de dama vestida de azul firmado por Charles Wautier. (Fig. 5)

La comparación con varios retratos de Michaelina nos reafirma en su atribución. El esquema corresponde con el Retrato de Don Antonio Pimentel de Prado que firma en $1646^{31}$, que citamos líneas atrás (Fig. 7). Es el mismo encuadre de la figura en el fondo neutro circundante, con el busto ligeramente ladeado y la cara y la mirada vueltas al espectador. Son dos rostros comparables, de análogo modelado; coinciden en la configuración de la barbilla y en la incidencia de la luz. Todo está equilibrado. En cambio, en los retratos de Charles Wautier, los rostros son más alargados y las bocas tienen un rictus particular, con el labio inferior ligeramente avanzado, tendiendo al prognatismo. Particularmente decisivo nos parece el diseño de los ojos, con esa mirada acuosa que soslaya la frontalidad; aspecto muy recurrente en Michaelina que se revela por ejemplo, en retratos como el del VIII Duque de Alburquerque Don Francisco de la Cueva (Barcelona, 1619-

\footnotetext{
30 Véase nota 7.
}

31 Véase nota 6. 


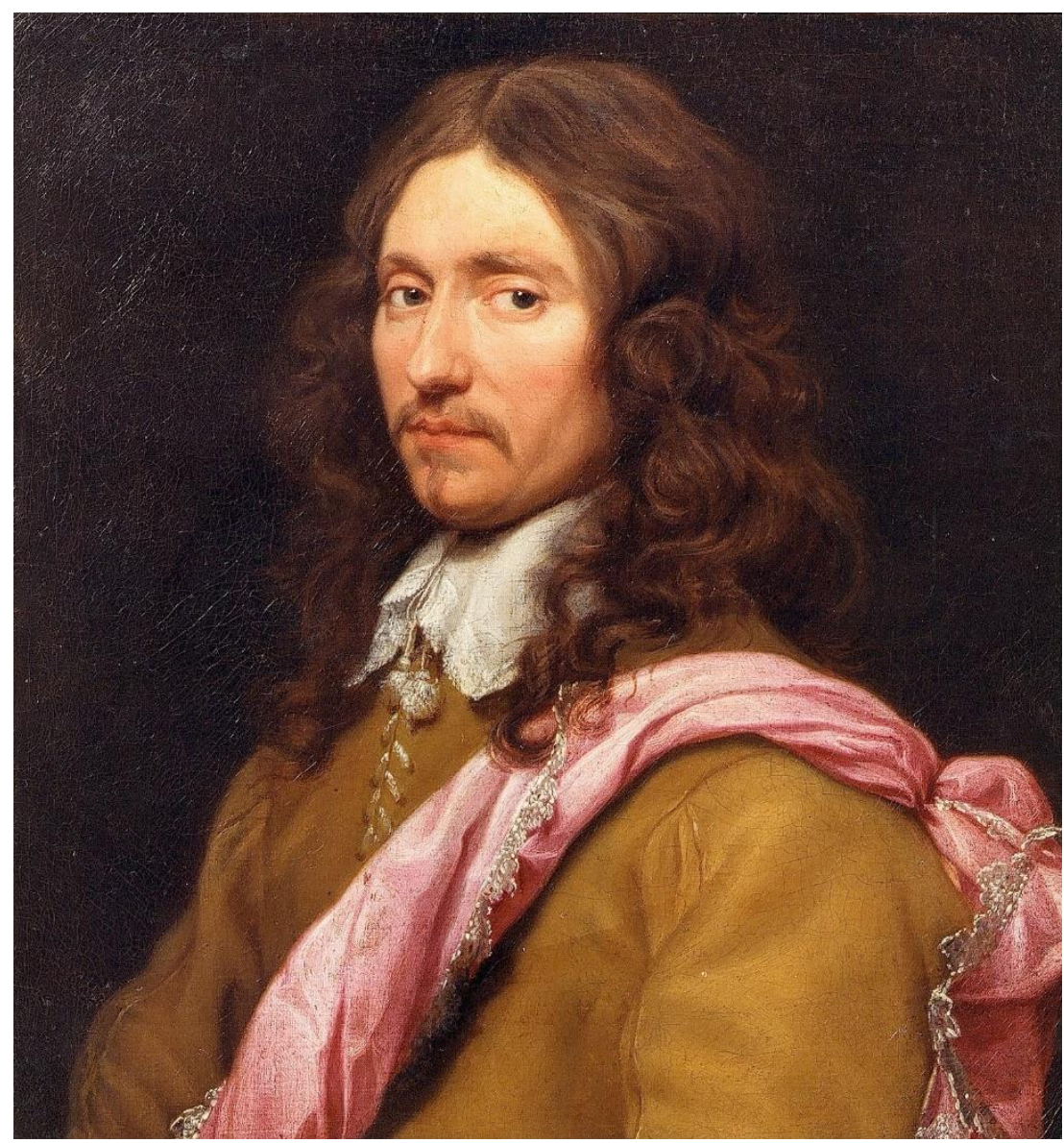

Fig. 7. Michaelina Wautier, Retrato de Don Antonio Pimentel de Prado, 1646. (Lienzo, 63 x 56,5 cm.) Bruselas, () Musées Royaux des Beaux Arts, (inv. n. ${ }^{\circ} 297$ )

Madrid, 1676) $)^{32}$, (Fig. 8) el del misionero jesuita Martino Martini (Trento, 1614-Hangzhou, 1661) ${ }^{33}$, el de su hermano el capitán de caballería Pierre Wautier (Mons, 1611-Bruselas, 1664) ${ }^{34}$, o el de la prodigio Anna Maria van Schurman (Colonia, 1607-Frisia, 1678) ${ }^{35}$. (Fig. 9) Si comparamos el rostro de ésta con el de nuestra dama, observamos una análoga y emotiva dulzura

\footnotetext{
32 (Lienzo, 68,5 x 56,2 cm.) ca. 1640-1643. Reino Unido, colección particular. Sanzsalazar, "Encarar el miedo", pp. 61-98.

33 (Lienzo, 69,5 x $59 \mathrm{~cm}$ ), firmado y fechado arriba, a la izquierda: "Michaelina Wautier fecit. 1654", y en caracteres chinos, de arriba a abajo, el nombre chino del retratado: "Wei Kunangguo", junto a la transcripción en alfabeto latino. N. Golvers, "Note on the Newly Discovered Portrait of Martini", en Martino Martini (1614-1661), Man of Dialogue, eds. Luisa M. Paternicò, Claudia von Collani, Riccardo Scartezzini, Simposio Internacional (Trento, 15/17-10-2014), (Trento: Università degli Studi, 2016), pp. 9-11; K. van der Stighelen, "Portrait of the Jesuit Martino Martini", en Michaelina Wautier 1604-1689, pp. $186-193$, cat. 8 .

34 (Lienzo, 73 × 58,5 cm.) Subyace el escudo de armas de la familia Wautier arriba a la izquierda. J. Sanzsalazar, "Michaelina Wautier y la boda de su hermano: Historia de un retrato identificado", Tendencias del Mercado de Arte, no 69, (enero 2014), pp. 90-94; K. van der Stighelen, "Portrait of a Military Commander (Pierre Wautier?)", en Michaelina Wautier 1604-1689, pp. 182-185, cat. 7.

35 (Lienzo, $120 \times 102 \mathrm{~cm}$.) Colección privada. Sobre la identificación de la retratada: J. Sanzsalazar, "Michaelina Wautier y la incomparable Anna Maria van Schurman: feminismo, arte y erudición en los Países Bajos en el siglo XVII", Tendencias del mercado del arte, (mayo 2018), pp. 86-91, fig. 1, como Retrato de Anna Maria van Schurman por Michaelina Wautier; Van der Stighelen lo considera un
} 


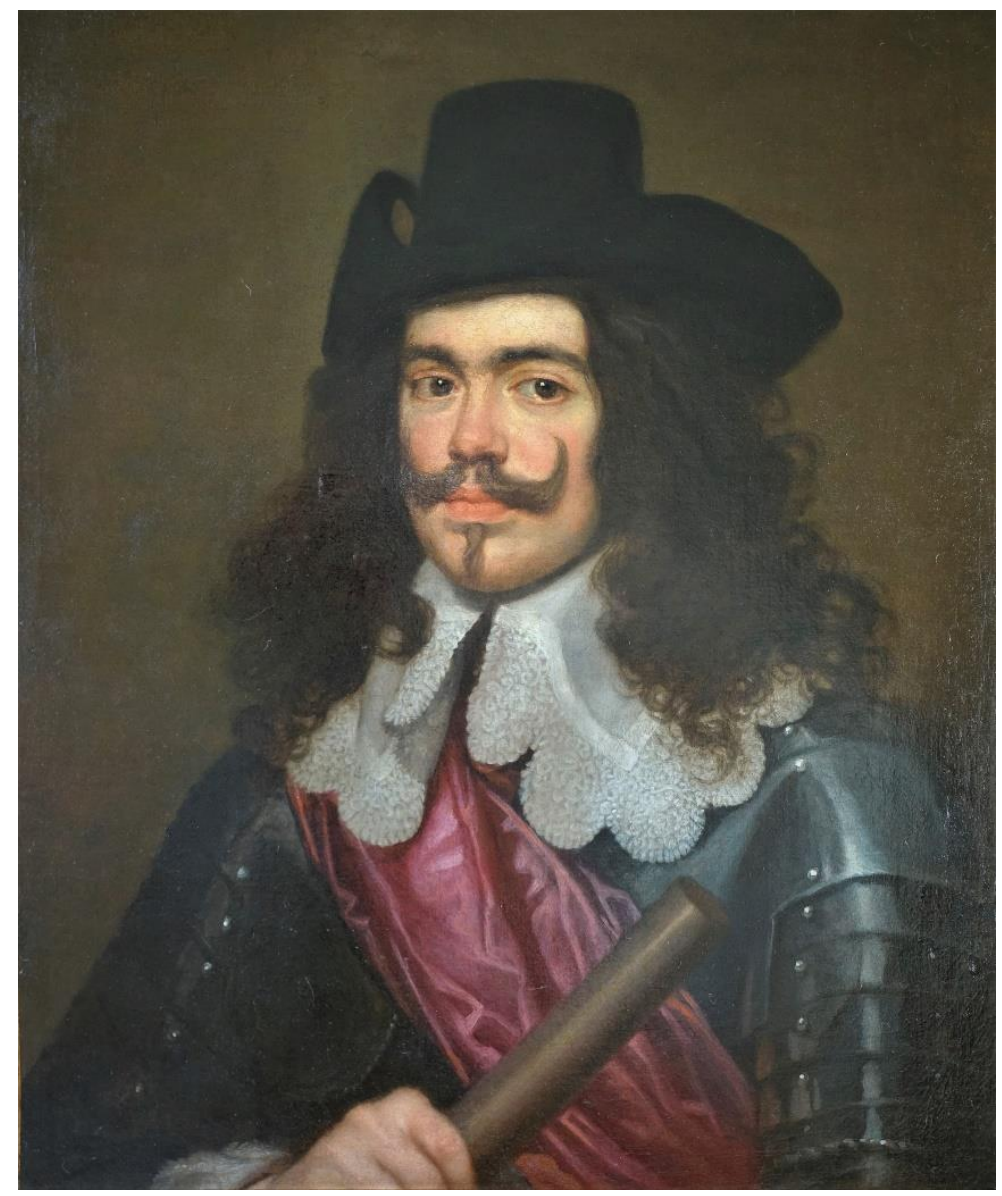

Fig. 8. Michaelina Wautier, Retrato de Don Francisco Fernández de la Cueva, VIII duque de Alburquerque, ca. 1640-1643. (Lienzo, 68,5 x 56,2 cm.) Reino Unido, colección particular. @ Foto autora

que se vuelve más fría y distante en el Retrato de dama vestida de azul que firma Charles Wautier. (Fig. 5) Michaelina prescinde de detalles que desvíen la atención, le interesa más la confrontación con el rostro, explora mejor los secretos del ser y logra aportar una mayor profundidad emocional al personaje. Para ella, lo más conmovedor está en los ojos, que son el espejo del alma. Dota así de una suave gravedad a sus retratados, con una melancolía característica, confiriéndoles una emotiva e íntima humanidad. Es lo que vemos en sus retratos. En el que estudiamos, la mirada está cargada de una hondura que nos acerca a la retratada, permitiéndonos percibir su vulnerabilidad. Tal capacidad para penetrar en el complejo interior de los individuos es para muchos la esencia misma de una categoría suprema en el arte del retrato.

La paleta utilizada es común a ambos hermanos. Utilizan los mismos materiales, algo lógico al vivir y trabajar juntos. El azul es muy característico, un pigmento que suele sufrir alteraciones presentando con el 


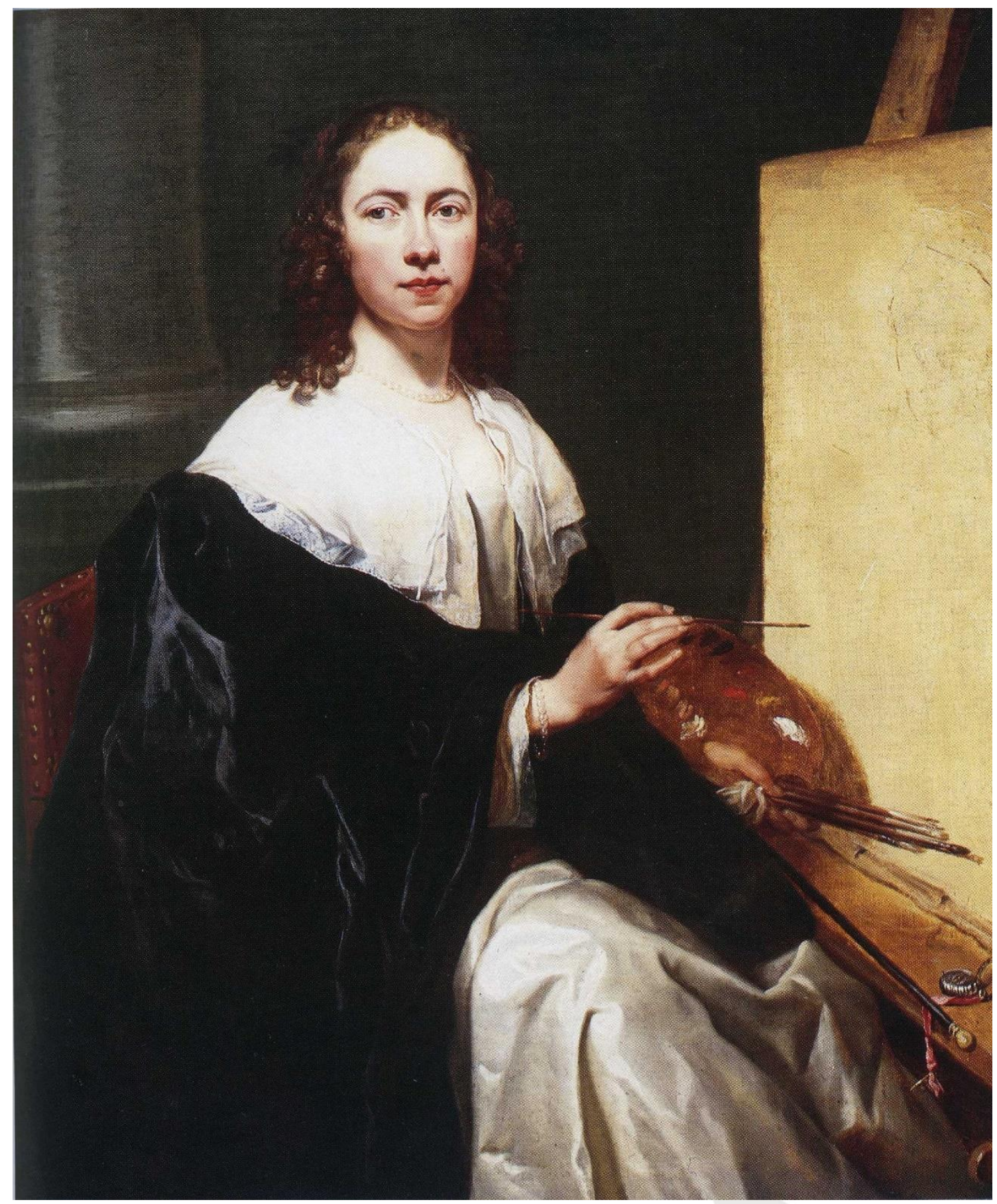

Fig. 9. Michaelina Wautier, Retrato de Anna Maria van Schurman, (Lienzo, 120 x 102 cm.) Colección privada. (C) Foto autora

tiempo una coloración blanquecina. El mismo azul está presente tanto en obras que se atribuyen a Charles: como son el Profeta o Apóstol del museo de Cambrai, la Vocación de San Mateo de Osterley Park y Toulouse, o el Cristo entre los doctores de colección privada belga; como a Michaelina: la Educación de la Virgen, la Anunciación de Marly-le-Roi o los Desposorios de 
Fig. 10. Michaelina Wautier, Estudio de Santa de busto, firmado. (Lienzo, 44,6 x 37,2 $\mathrm{cm}$.) Paradero actual desconocido. (C) Foto autora

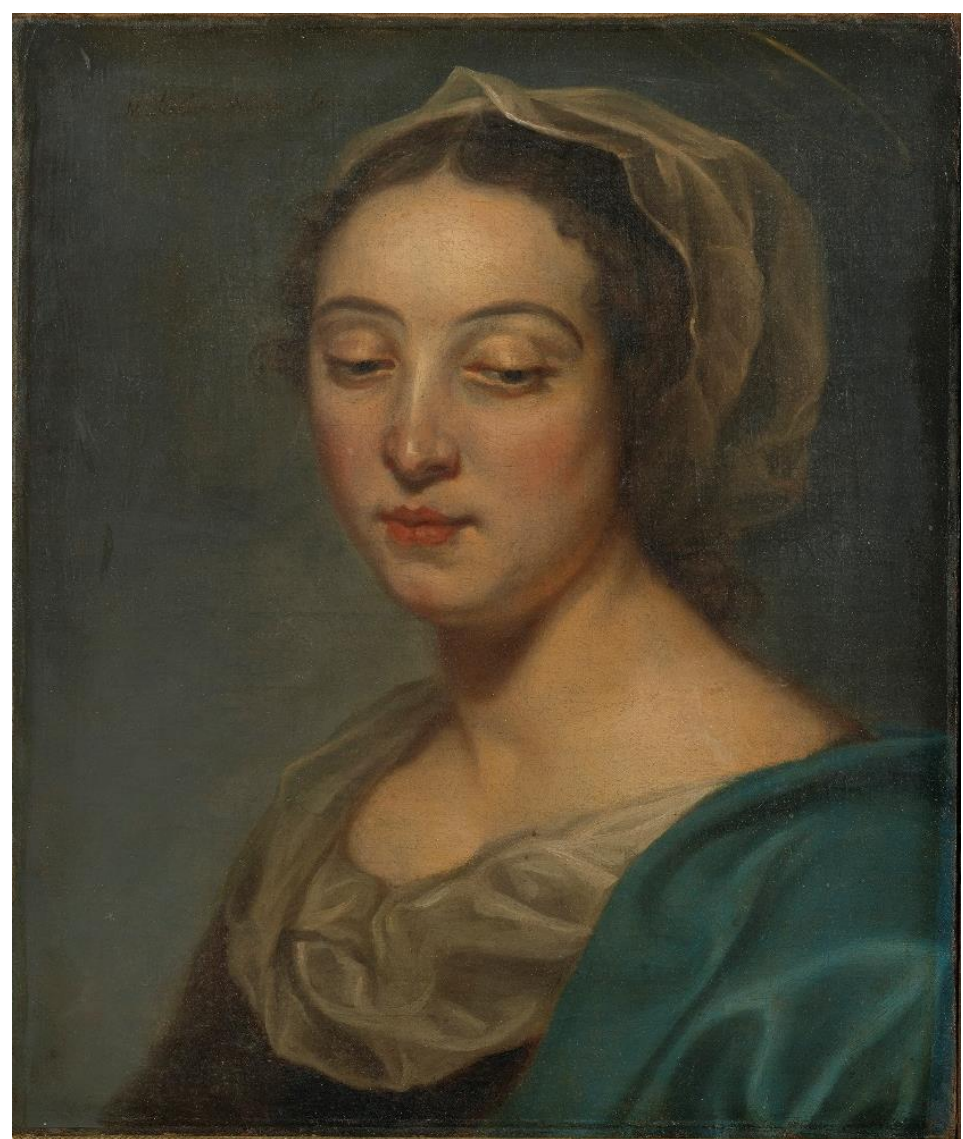

Santa Catalina en Namur. En esta última se ha apuntado el uso de bermellón en los labios y de una combinación de rojo y azul en los mantos ${ }^{36}$, que es idéntica en el retrato que estudiamos. Muy sugerente es la comparación con el recientemente descubierto Estudio de una Santa de busto firmado por Michaelina ${ }^{37}$. (Fig. 10) Aunque es pintura de carácter más abocetado, posiblemente un trabajo preparatorio para una composición mayor, anida un mismo espíritu en la manera de componer, reiterando la disposición del busto, la línea del cuello y el manto azul sobre el hombro izquierdo.

Por la sutil riqueza del atuendo cabía situar a la retratada en un contexto aristocrático. Fue la comparación con los retratos conocidos de la princesa Mary Henrietta Stuart lo que dio la clave para su identificación. Su rostro, por edad y por la importancia de la nariz, es muy cercano a los retratos que de ella hizo en 1659 Adriaen Hanneman (La Haya, 1603-1671) ${ }^{38}$, (Fig. 11) y

\footnotetext{
36 Véase nota 7

37 (Lienzo, 44,6 x 37,2 cm.) firmado arriba, a la Izquierda: "Michaelina Wautiers fecit". París, colección particular. París, Christie's, (28-11-2019, cat. no 379).

38 (Lienzo, 62 x $43 \mathrm{~cm}$ ). firmado y fechado: "An¹659/ A Hanneman/ F.", en la Scottish National Portrait Gallery de Edimburgo (inv. no PG 1308). Tomado de éste está el ejemplar correspondiente al grabado, fechado en 1660 (lienzo, 138,4 x 101 cm.) firmado y fechado: "An¹660/Adr. Hanneman F.", en colección privada del Reino Unido. Un tercero, póstumo, muestra a la princesa acompañada por un sirviente (Lienzo, 130,5 x 120,8 cm.) conservado en el Koninklijk Kabinet van Schilderijen Mauritshuis
} 


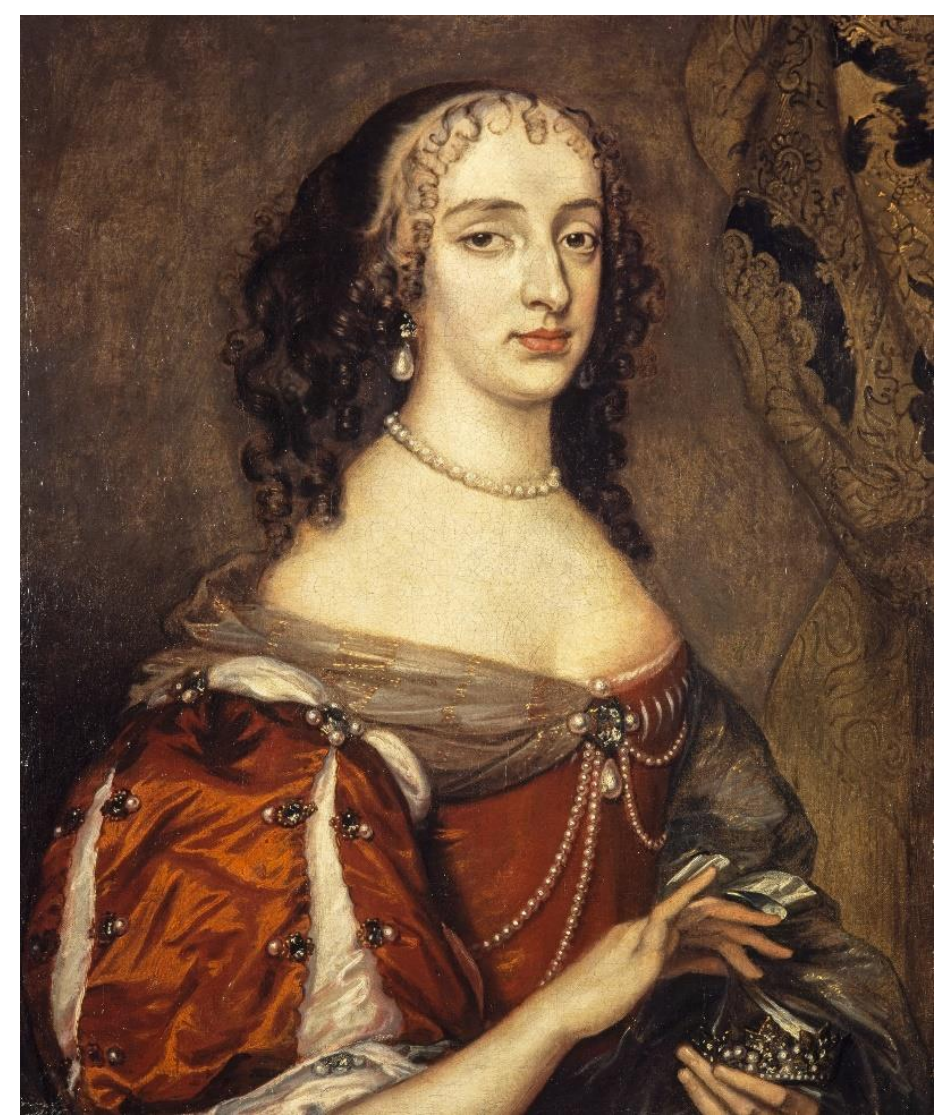

Fig. 11. Adriaen Hanneman, Retrato de Mary Henrietta Stuart, Princesa Real y Princesa de Orange, 1659. (Lienzo, 62 x $43 \mathrm{~cm}$.) Edinburgh, (C) Scottish National Portrait Gallery (inv. PG 1308)

los grabados a media tinta que reprodujo William Faithorne (Londres, 1616$1691)^{39}$. (Fig. 12) Michaelina suaviza ligeramente los rasgos y magnifica la belleza de la princesa, un proceder que se manifiesta también, por ejemplo, en el Retrato del duque de Alburquerque (Fig. 8), al que se ve más apuesto que en los retratos de la época virreinal ${ }^{40}$. Nos preguntamos si a esto se referiría Florent du Rieu, con aquél "mucho más que la natura" del poema ya citado.

La princesa Mary Henrietta era viuda desde los diecinueve años y no alcanzó los treinta: murió de viruela la víspera de Navidad de 1660 . Tuvo una vida corta y poco feliz. La casaron siendo niña por imperativos políticos. Llegó a La Haya sin hablar el idioma y se encontró con una corte que le era hostil. Su único hijo, el futuro Willem III (La Haya, 1650-Londres, 1702), nació pocos días después del fallecimiento de su marido. Carlos I había sido

de La Haya (no inv. 429). Onno Ter Kuile, Adriaen Hanneman: 1604-1671: een Haags portretschilder, (Alphen aan den Rijn: Canaletto, 1976), p. 101, cats. 58, 59a, 78a, figs. 35, 36, 37; Quentin Buvelot, "Een bijzonder portret van Maria Stuart door Adriaen Hanneman in het Mauritshuis", en Face Book. Studies on Dutch and Flemish Portraiture of the 16th-18th Centuries. Liber Amicorum presented to Rudolf E.O. Ekkart on the occasion of his 65th Birthday, eds. Edwin Buijsen, Charles Dumas, y Volker Manuth, (Leiden-Den Haag: Charles Dumas, 2012), pp. 373-380 y fig. 1.

39 (Mezzotinta sobre papel, 29,21 x 22,86 cm.) Scottish National Portrait Gallery en Edimburgo ( $n^{\circ}$ inv. SP II 67.5). Con la inscripción: "Adrian Hanneman pinxit 1660/ Willm. Faithborne junio fecit/ Cum Privilegio Regis/ Sold by R. Tomson at ye Sun in Beldford-berry \& E. Cooper at the three Pidgeons in Bedfor Street". Con la leyenda: "Her Royall Highness Mary Princess of Orange, eldest Daughter of KING Charles ye First, \& Mother to our present souvereigne K. WILLIAM ye Third".

40 Sanzsalazar, "Encarar el miedo ", pp. 69, 72, y fig. 9. 
Fig. 12. William Faithorne siguiendo a Adriaen Hanneman, Retrato de Mary Henrietta Stuart, Princesa Real y Princesa de Orange, 1660. Grabado. Edimburgo, (C) Scottish National Portrait Gallery (inv. SP II 67.5.)

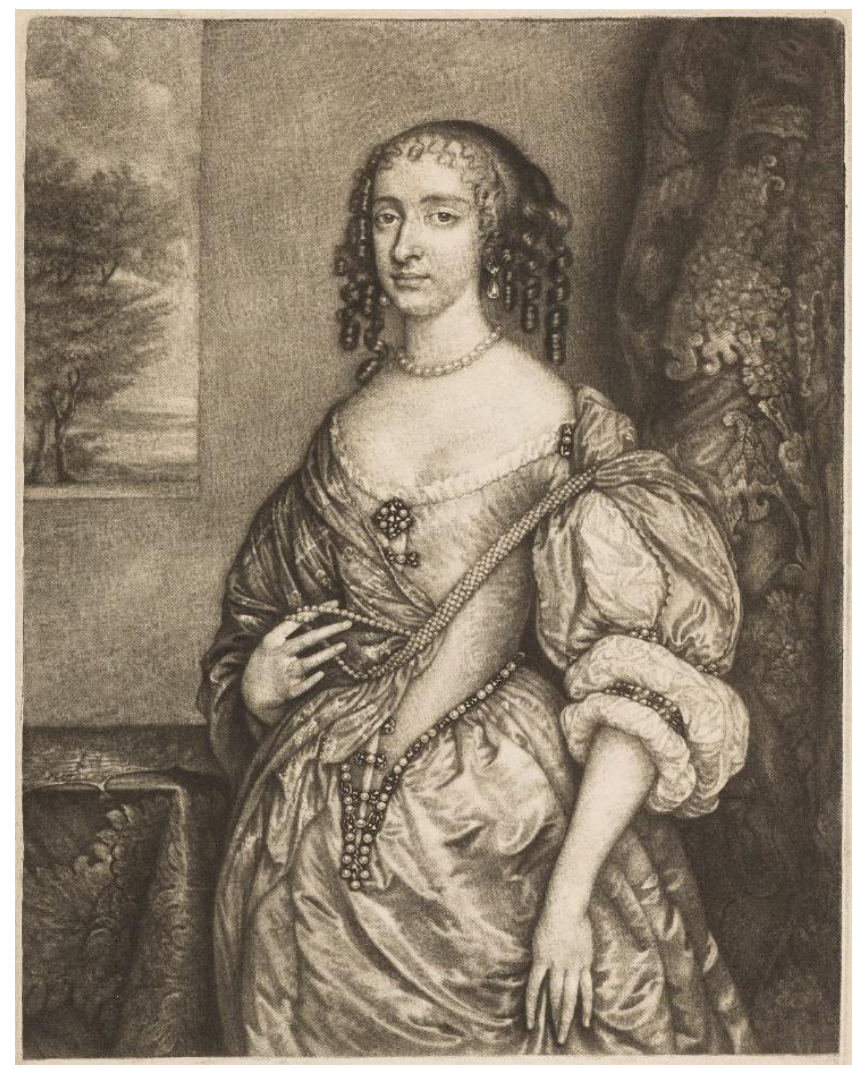

decapitado en Londres unos meses antes, y dar asilo a sus hermanos no contribuyó a su popularidad. Vivió entregada a la causa realista y a la restauración de los Estuardo en Inglaterra. Los conflictos con su suegra, Amalia de Solms (Braunfels, 1602-La Haya, 1675), por la tutela del heredero la condujeron a retirarse a Breda, pasando varias semanas en el balneario valón de Spa (1654) y realizando diversas visitas a su hermano Carlos II en Colonia y Fráncfort (1655), y a su madre Henrietta Maria en París (1656).

En Bruselas estuvo en varias ocasiones en las que bien pudo hacerse retratar por Michaelina Wautier. Sabemos que allí acudió el 14 de diciembre de 1658, acompañando a su hermano Carlos II que había sido solicitado para entrevistarse con los españoles en vistas de buscar la caída de Cromwell ${ }^{41}$. Sería, no obstante, más probable que la princesa tuviera más tiempo de posar en 1660, fecha a la que nos conducen, por otro lado, las evidencias de la indumentaria. En este año, en que se fraguaba la vuelta de Carlos II al trono de Inglaterra, localizamos a Mary Henrietta en Bruselas durante varias semanas. Así lo demuestran cuatro cartas remitidas por ella desde allí entre el 24 de enero y el 18 de febrero de $1660^{42}$. Desde

\footnotetext{
${ }^{41}$ Scott, The travels, 1907, pp. 266 y 267.

42 Las cartas están dirigidas a los Estados Generales de Holanda, al Parlamento de Orange y a la corte de Holanda. Véase el manuscrito copiado por el secretario Nicolas Oudart conservado en La Haya, Koninklijke Verzamelingen, Archief Mary Stuart, 15a, A15-XI B3, Letters 310-313, fols. 148r-149v. (En
} 
principios de año se sabía que el partido realista iba ganando fuerza en Inglaterra; la popularidad de Carlos II iba creciendo hasta tal punto que se colgaba su imagen en las calles de Londres y se esperaba con ansia su regreso. La Restauración de los Estuardo era una realidad. Tras Bruselas, los tres hermanos se reunieron de nuevo en Breda, donde culminaron las negociaciones en el mes de mayo con la declaración oficial de Carlos II como rey de Inglaterra, Escocia, Francia e Irlanda. Recibidos en la Haya con gran magnificencia, Carlos II embarcó finalmente para Inglaterra a finales de mes y, aclamado por el pueblo a su llegada a Dover, emprendió al poco su camino hacia Londres, a donde llegó el 29 de mayo, el día en que cumplió los treinta y uno, después de diecisiete años de ausencia ${ }^{43}$. La princesa de Orange llegó a Londres al final del verano ${ }^{44}$, y murió a los tres meses, dejando a Carlos II y a la corte muy afligidos. Perdían un "alma noble" que siempre demostró su abnegación y prestó inmenso apoyo y consuelo a sus hermanos "en los momentos de mayor desgracia"45. Si Mary Henrietta posó para Michaelina meses antes, entre enero y febrero de 1660 como parecen confirmar los indicios apuntados, sería posible que el retrato fuera el último tomado del vivo de esta princesa, tan inmortalizada desde su más tierna infancia, de la que no se conocen, en cualquier caso, retratos posteriores, aunque sí póstumos ${ }^{46}$.

\section{El futuro Carlos II y los Wautier. Reflexiones sobre una hipótesis}

Dado que los Wautier retrataron a dos de los hermanos Estuardo en Bruselas, nos preguntamos -y no sería extraño- si Carlos II también habrá acudido a ellos en los largos meses de exilio que precedieron su restauración al trono. A este respecto nos llama la atención la siguiente entrada de un retrato vendido en Londres en 1691, que cita: "El Rey Carlos II por Wouters"47. Parece poco probable que se haga referencia a Frans Wouters (Lier, 1613-Amberes, 1659), pintor conocido por sus paisajes y

web:

http://resources.huygens.knaw.nl/media/stadhoudersvrouwen/marystuart1/A15a-004.PDF, consultada: 11 de noviembre de 2020)

43 Scott, The travels, 1907, pp. 447, 458, 461, 462, 464, 469-470, 473, 476, 477

44 "The Princess Royal has arrived (28 sept)". Calendar of State Papers, Domestic Series, of the Reign of Charles II: 1660, ed. Mary Anne Everett Green, (London: H. M. Stationery Office, 1860), p. 277, vol. XVI, pp. 259, 305.

45 "Her Death was a most sensitive affliction to the king and all the court, being a lady of a noble soul, of admirable virtues, and all the princely endowments, and one who had been the great support and comfort to her three brothers in the time of their greatest distress". Testimonio de V. Echard en 1660. Lawrence Echard, The History of England from the restoration of King Charles the Second to the conclusion of the reign of King James the Second and establishment of King William and Queen Mary, (London: Jacob Tonson, 1718), p. 41; Letters of Philip, second Earl of Chesterfield to several celebrated individuals of the reign of Charles II, James II, William III, and Queen Anne, with some of their replies, (London: E. Lloyd, 1829), p. 81.

${ }^{46}$ Véase notas 37,38 y 39.

47 "King Charles the II. by Wouters". At the Bell-Tavern over against the Gate-House in Kings-Street Westminster. Will be Exposed to Sale a curious collection of Paintings; being most originals, by the best masters of Europe, on Tuesday, Wednesday, Thursday and Friday, the 13th, 14th, 15th and 16th of this instant October, 1691, lot. no 225, (En web: Getty Provenance Index@), Sale Catalog Br-A104, lot. 225). 


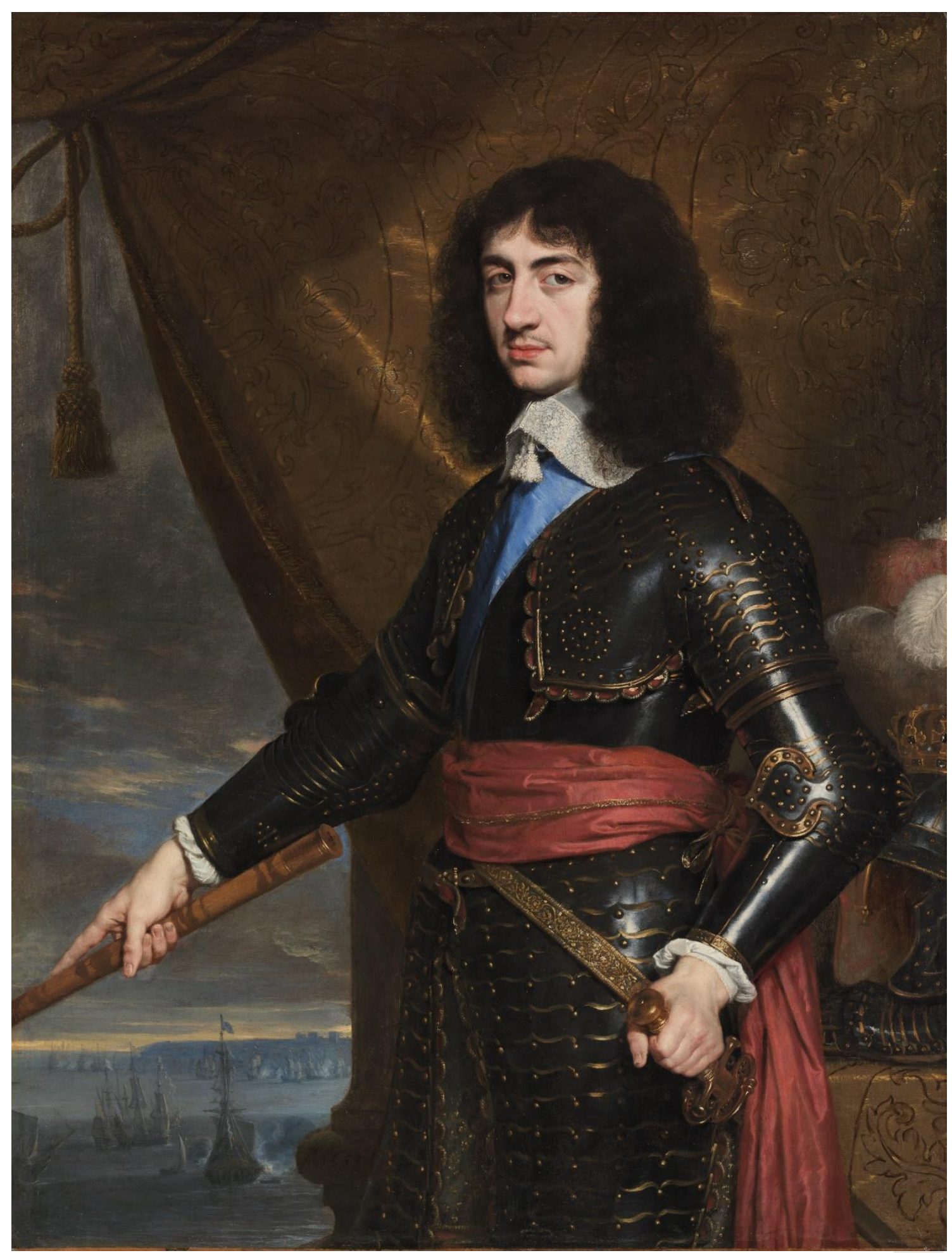

Fig. 13. Philippe de Champaigne, Retrato de Carlos II de Inglaterra, "A ${ }^{\circ} .1653 "$. (Lienzo, 129,5 x 97,2 cm.) Ohio, (C) Cleveland Museum of Art, The Elisabeth Severance Prentiss Collection, (inv. 1959.38.) 
pinturas de gabinete, no por sus retratos ${ }^{48}$. De otra parte, no sería la primera vez que los Wautier se confundieran con este pintor, dado el parecido de sus apellidos. En cualquier caso, Carlos II pudo haber tenido innumerables oportunidades para hacerse retratar por los Wautier entre 1656 y 1660 . Aunque hasta ese último año residía oficialmente en Brujas, partió nada más llegar y siempre estaba en Bruselas ${ }^{49}$. Envió cartas desde allí en abril y junio de $1657^{50}$, en noviembre de $1658^{51}$, y en febrero y marzo de 165952; si bien su traslado no sería efectivo hasta finales de diciembre de $1659^{53}$. Desde abril de 1658 se decía en Londres que todo Flandes estaba "lleno de soldados de Charles Stuart"54. Fue en Bruselas donde Carlos II se enteró de la muerte de Cromwell en septiembre y, viendo su vuelta más cerca, permaneció en la ciudad mientras se fraguaba su restauración al trono. Su hermana Mary Henrietta estuvo junto a él varias semanas a principios de 1660, como se ha comentado; a finales de marzo le proponen volver a Inglaterra para reinar ${ }^{55}$, y permaneció en Bruselas hasta su partida a Breda el 12 de abril ${ }^{56}$.

En cualquier caso, nos preguntamos a qué pintor estaría esperando Carlos II cuando, en carta del 7 de febrero de 1660, estando su hermana junto a él en Bruselas, aludía a un retrato suyo que había prometido a una cierta "Madame Boude", dama de cámara de la Reina Madre en París. Se excusaba por el retraso en enviárselo, apuntando que "el pintor no está ahora en la ciudad, pero volverá en pocos días"57. Durante sus años de exilio en los

\footnotetext{
48 De tratarse de un retrato por Frans Wouters, representaría a Carlos II siendo niño, pues dataría de entre 1637 y 1641 , periodo en el que estuvo en Londres como pintor de su cámara cuando era príncipe de Gales. Jos F. van den Branden, "Frans Wouters, kunstschilder, 1612-1659", Annales de l'Académie Royale d'Archéologie de Belgique, (1872), pp. 211-212. En la modalidad de retrato sólo se le supone el suyo propio, en base a la inscripción "Frans Wouters pinxit." de su grabado por Peter de Jode. Londres, British Museum, (no inv. Sheepshanks.7410).

49 Carlos II vivió en Brujas desde el 22 de abril de 1656 al 15 de marzo de 1659. Al llegar, parte a Bruselas a entrevistarse con los españoles y no tiene prisa por volver a su reclusión en Brujas. Scott, The travels, pp. 293, 294.

50 "Order, signed by Charles II, and contresigned by sir Edw. Walker, respecting the procedency of captains in the regiment of lieut.-gen. John Middleton", Bruxelles, 4 June, 1657. Catalogus codicum manuscriptorum Bibliothecae Bodleianae ..., Partis quintae, Fasciculus primus, (Oxonii: Typographeo académico, 1862) p. 136, n 44.

51 El 7 de noviembre de 1658, Charles II envía carta desde Bruselas a Mr. Crawton, a Rotterdam, a propósito de cuestiones de religión. "A Letter from King Charles the Second, third Monarch of Great Britain, to Mr. Carton, late Minister of the English Church in Rotterdam, Dated at Brussels, November 7th, 1658". A Catalogue of the Library of the London Institution, systematically classed. Preceded by an historical and bibliographical account of the establishment, vol. II, (London: C. Skipper and East, 1840), p. 325.

52 Carta enviada a Mr. Goston, Londres, el 18 de marzo de 1659. Thurloe, A Collection of the State Papers, p. 628.

53 Paul Rapin de Thoyras, The History of England, vol. II, (London: James and John Knapton, 1726), pp. 608 y 610; F. S. Thomas, Historical Notes 1603-1714, vol. II, (London: G. E. Eyre and W. Sporriswoode, 1856), p. 632.

54 Scott, The travels, p. 298.

55 El 30 de marzo, recibe una carta del General Monk sobre su vuelta a Inglaterra para reinar, a la que contesta el 27 de abril, nombrando a Monk Capitan General. Rapin, The History, II, p. 616.

56 Véanse las cartas fechadas desde Bruselas, el 10 de abril de 1660: "The Kings removes to Breda on Monday next, where the States of Holland will not be so unwilling to find him, as formerly, they having now a better opinion on his affairs". Thurloe, State Papers, p. 880. "Letter and declaration of his Majesty to the Court of Common Council of the city of London, Breda, April, 1660", cit. Catalogue of the Printed Books in the Library of the Faculty of Advocates, vol. II, (London, 1873), p. 171 (Charles II).

57 Carta enviada por Carlos II desde Bruselas, el 7 de febrero de 1659, a su hermana Henriette-Anne, a París: "Dites a $\mathrm{M}^{\mathrm{me}}$ Boude que je luy envoyeray bientot mon portrait. Présentement le peintre n'est pas en cette ville, mais il reviendra dans peu de jours". Charles de Baillon, Henriette-Anne d'Angleterre,
} 
Países Bajos españoles, Carlos II se hizo retratar a menudo, tanto en Bruselas como en Amberes. Reproducir y divulgar su imagen formaba parte de una estrategia propagandística de afirmación de su poder ${ }^{58}$, y más en los momentos previos a la Restauración de su monarquía. Por cronología cabe excluir que Carlos II aluda a la mayor parte de sus retratos conocidos. El de Jan van den Hoecke (Amberes, 1611-1651) debe datar de entre los años 1647 y 1651, cuando el pintor acompaña al archiduque Leopoldo Guillermo a Amberes $^{59}$. En esta misma época cabe situar el de Pieter van Lint (Amberes, 1609-1690), que lo dibujó siendo más joven para un grabado60. El espléndido retrato que le hizo Philippe de Champaigne (Bruselas, 1602Paris, 1674) se hizo en París, y está fechado en $1653^{61}$. (Fig. 13) El grabado de Wallerant Vaillant (Lille, 1623- Ámsterdam, 1677) lleva la fecha de $1656^{62}$. Cabe preguntarse si podría tratarse de Peter Thys (Amberes, 16161677), que le hizo un retrato de cuerpo entero al que el pintor alude en su correspondencia el 21 de julio de 166063; o de Gonzales Coques (Amberes, 1614-1684), del que se conocen dos grabados, uno de los cuales fechado en $1660^{64}$. También cabe plantearse si Carlos II no se referiría a Wautier,

duchesse d'Orléans: sa vie et sa correspondance avec son frère Charles II, (Paris: Perrin et cie, 1886), p. 32, p. 32; J. Cartwright (Mrs Henry Ady), Madame: a life of Henrietta, daughter of Charles I and duchess of Orleans, (London: Seeley, 1894), p. 53; Cyril Hugues Hartmann, Charles II and Madame, (London: W. Heinemann, 1934), p. 10; C. Hugues Hartmann, The King, my brother, (London: W. Heinemann, 1954), p. 10; Bryan Bevan, Charles II's Minette: Princess Henriette-Anne, Duchess of Orleans, (London: Ascent Books, 1979), p. 34.

${ }^{58}$ La reciente exposición en la Royal Academy de 2017 se ha centrado en la imagen de Carlos II tras la restauración de la monarquía. Charles II. Art and Power, Cat. Exp., Royal Academy (London: Royal collection Trust, 2017).

${ }^{59}$ Según el grabado con la inscripción: "I van Hoecke pinxit/ I Meÿssens ex. / Fred Bouttats Sculpsit", y la leyenda: "CAROLVS SECVNDUS DEI GRATIA. MAGNAE BRITANNIAE FRANCIAE ET HIBERNIAE REX, etc." No se conoce el original sino réplicas o copias que conserva la National Portrait Gallery de Londres ( $n^{\circ}$ inv. D18449 y D18452) y la Goverment Art Collection (no inv. 3731). Localizamos en ventas antiguas un ejemplar registrado como original: "Van Hoecke. Charles II, small half length. 2' 4" x 2". Londres, Machel Stace Auction House, (enero 1812, lot. 3) (En Web: Getty Provenance Index@), Sale Catalog $\mathrm{Br}-935$, lot 0003).

60 Según el grabado con la inscripción: "Petr. a Lisabethis Sculp / Petr van Lint delin. / Petr de Iode excudit."; y la leyenda: "CAROLVS SECVND.D.G. MAG. BRITAGN. FRANC. SCOT. ET HIBERN. REX". National Portrait Gallery, Londres ( $n^{\circ}$ inv. D18453).

61 (Lienzo, 129,5 x 97,2 cm.) fechado: "A०.1653". Cleveland Museum of Art, The Elisabeth Severance Prentiss Collection, (no inv. 1959.38). Bernard Dorival, Philippe de Champaigne, 1602-1674: La vie, I'oeuvre et le catalogue raisonné de L'oeuvre, (Paris: Léonce Laget Libraire, 1976), cat. 157; European paintings of the 16th, 17th, and 18th centuries. (Cleveland: Cleveland Museum of Art, 1982), p. 59.

62 Con la inscripción: "W. Vaillant fe.", y la fecha: "1656". Londres, Royal Collection (RCIN 602399). Freeman O'Donoghue, Catalogue of Engraved British Portraits Preserved in the Department of Prints and Drawings in the British Museum, (London: by order of the Trustees, 1908), p. 138 (Charles II).

63 Retrato de Charles II de cuerpo entero por Peter Thys (lienzo, 224,30 x $135 \mathrm{~cm}$ ). Reino Unido, Goverment Art Collection, ( $n^{\circ}$ inv. 3817), en depósito en la embajada británica en La Haya. (En web: https://artcollection.culture.gov.uk/artwork/3817/, consultada: 7 de diciembre de 2020). En carta a Guillermo Federico de Oranje del 21 de julio de 1660, el pintor se excusa del retraso en la entrega de sus encargos por causa "de las pinturas para Su Majestad de Inglaterra y príncipes" ["alsoo gedurich hebbe moeten schilderen voor sijne magesteijt van Engelant ende princen, niet tegenstaende seijde $\mathrm{V}$ $E^{\prime \prime}$. La Haya, Koninklijk Huisarchief (KHA), Archief Graaf Willem Frederik van Nassau-Dietz, ( $n^{\circ}$ inv. A25-243). Véase al respecto: Katrien Daemen-de Gelder y Jean Pierre Vander Motten, "Peeter Thijs (1624-77)- An Antwerp Portraitist under the Patronage of William Frederick of Nassau-Dietz (161364)", Zeitschrift für Kunstgeschichte, 72, (2009), pp. 129-130, nota 10.

${ }^{64}$ Grabado con la inscripción: "Gonsales Coques pinxit /Petrus de Iode Sc/ Gaspar de Hollander excudit Antwerpiae 1660". Londres, Royal Collection, (no inv. RCIN 602410). Existe otro, de tres cuartos de perfil, una mano en el yelmo y la otra en la cadera con la inscripción: "Gonsales Cocques pinxit/ Q. Boel fecit aqua fortis". Londres, Royal Collection, (no inv. RCIN 602413). No se conocen las pinturas correspondientes. En una antigua venta figura una así descrita: "Gonzales. Portrait of King Charles II". Propiedad de Georges Watson Taylor. Londres, Harry Phillips, (18-03-1813, no inv. 45), adquirido por Fletcher. (En web: Getty Provenance Index@), Sale Catalog Br-1082, no lot 0045). 


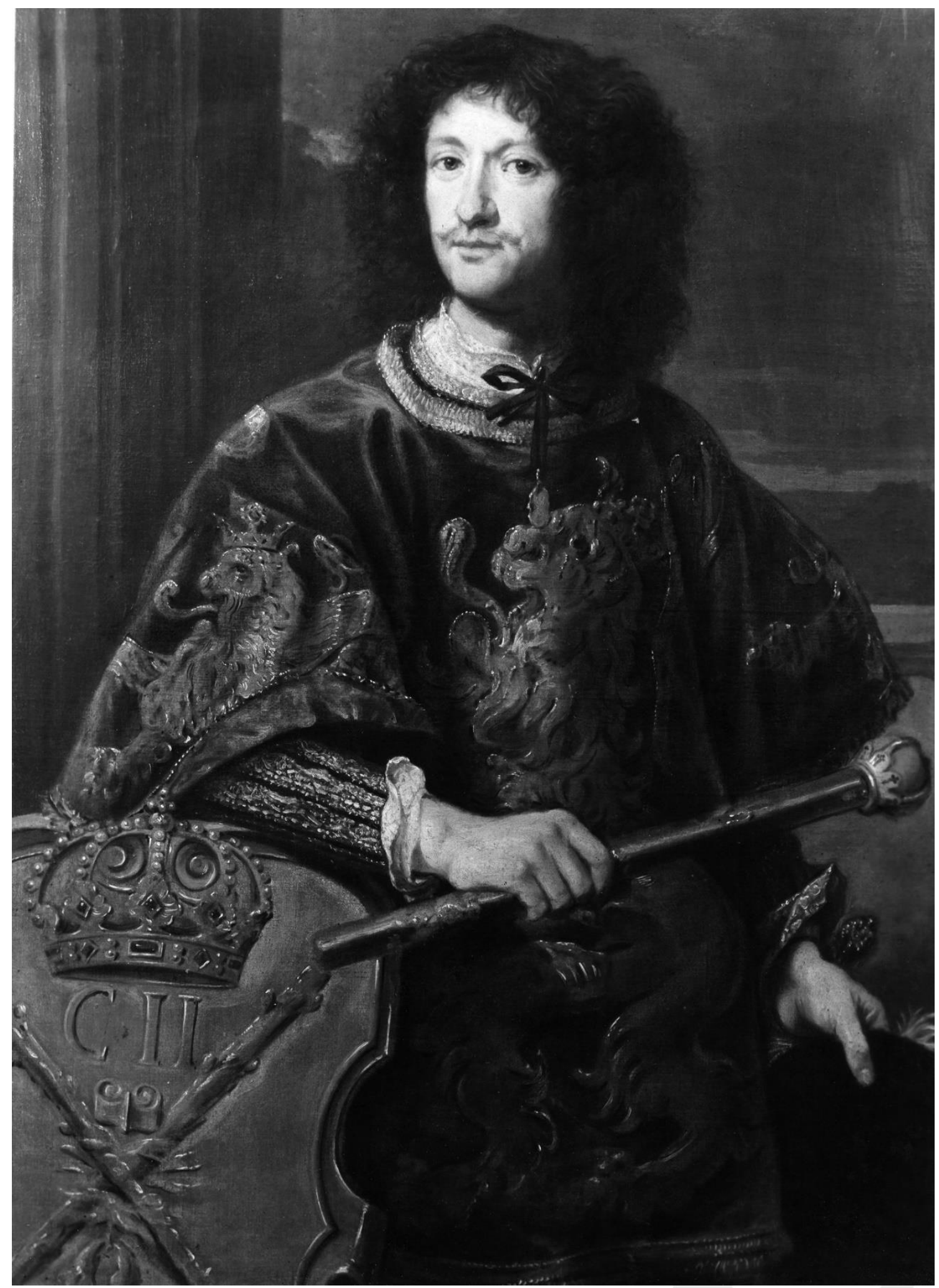

Fig. 14. Charles Wautier, Aquí identificado como Retrato de Carlos II de Inglaterra, ca. 1656-1660. (Lienzo, 118 x $87 \mathrm{~cm}$.) Amberes, (C) Koninklijk Museum voor Schone Kunsten (inv. n. ${ }^{\circ} 5028$ ) 
cuya consideración en estos momentos en Bruselas era notoria y para quienes posan sus hermanos.

En este sentido, el museo de Bellas Artes de Amberes conserva un lienzo atribuido a Charles Wautier que se tiene tradicionalmente por Retrato de un heraldo de Carlos II (Fig. 14), pintura donada en 1948 por la asociación Artibus Patriae ${ }^{65}$. El retratado lleva un bastón en la mano derecha y apoya el brazo sobre un escudo ornado con una corona e inscrito con las iniciales del rey. Viste un tabardo, una especie de túnica o poncho que habitualmente llevaban en las ceremonias los heraldos y reyes de armas. Sin embargo, esta prenda la vestían también los soberanos, y los heraldos la llevaban en imitación de sus señores, por lo que contemplamos la hipótesis de que el personaje de este retrato se trate, en realidad, del propio Carlos II. Que el tabardo con los blasones era usado por los reyes, lo prueba el llamado Sir Thomas Holme's Book of Arms, manuscrito británico del siglo XV que contiene versos e ilustraciones coloreadas donde están los reyes vestidos con tabardos, muchos de ellos blasonados con el león de Inglaterra como en el retrato en cuestión ${ }^{66}$. En otro atribuido a Peter Lely de la Royal Society de Londres (inv. n.o RS.9724), Carlos II viste bajo su manto un tabardo, con dos cabezas de león sobre los hombros. De otra parte, el rostro se reconoce al compararlo con el Retrato de Carlos II por Philippe de Champaigne del museo de Cleveland (Fig. 13). Si bien Wautier ofrece una imagen más dulcificada del rey, suavizando la dureza de sus facciones, se le identifica por el característico cabello negro y rizado, el fino bigote y los ojos grandes.

Tiene sentido que Carlos II posara para los artistas más relevantes del momento buscando afianzar su imagen de heredero de la corona británica, y por ello, -siguiendo a su hermano James- también contara con un retrato hecho por Charles Wautier, uno de los retratistas más reconocidos en Bruselas a mediados del siglo XVII. Como también tiene sentido que su hermana, la princesa, Mary Henrietta Stuart, posara para la hermana del pintor, Michaelina. Cabe imaginarlas frente a frente, con la intimidad que desprende el retrato. Michaelina logró plasmar un retrato del alma, que comunica el sentir de lo vivido. Su atribución se justifica por las analogías apuntadas con las obras conocidas, por la reiteración de esquemas y recursos característicos en términos de encuadre, fondo, posición, configuración del rostro, uso de la luz y colorido; pero es sobre todo la mayor perfección y equilibrio lo que invita a considerarlo como obra de Michaelina más que de Charles, pues ella está dotada de una mayor capacidad de profundizar en la psicología del personaje, mostrándonos con

65 (Lienzo, $118 \times 87$ cm.; no inv. 5028 ; Cliché KIK-IRPA: B115393). Paul Vandenbroeck, Erik Vandamme y Yolande Morel-Deckers, Catalogus Schilderkunst Oude Meesters, (Antwerpen: Koninklijk Museum voor Schone Kunsten, 1988), p. 420.

66 Sir Thomas Holme's Book of Arms. London, Bristish Library, Harley MS4205. (En web: http://www.bl.uk/manuscripts/Viewer.aspx?ref=harley ms 4205 fs001ar, Consultada: 5 de junio de 2021). 
la expresión de los ojos toda su vulnerabilidad. La pintora nos conduce suavemente y sin distracciones a entrar en las entrañas de Mary Henrietta Stuart, volviendo palpable el peso de su sacrificio y un atisbo de esperanza por el éxito inminente de la causa a cuya sombra siempre vivió. No deja de ser significativo que los Wautier retrataran a los tres hijos mayores de Carlos I de Inglaterra, como lo hiciera Van Dyck años atrás. Se confirma así la importante posición de estos hermanos pintores como retratistas en la Bruselas del siglo XVII, y la realidad de un prestigio olvidado hasta fechas recientes, cuya dimensión sigue, aún, tomando forma en la actualidad. 
Bibliografía:

Anvers 2018: Michaelina Wautier 1604-1689. Glorifying a Forgotten Talent, dir. Katlijne van der Sitghelen, Cat. Exp., (Anvers: Rubenshuis-MAS, 2018).

Baillon 1886: Charles, comte de Baillon, Henriette-Anne D'Angleterre: Duchesse D'Orléans. Sa Vie et sa correspondance avec son Frère Charles II, (Paris: Perrin et cie, 1886).

Barnes et al. 2004: Susan J. Barnes, Nora de Poorter, Oliver Millar y Horst Vey, Van Dyck. A Complete Catalogue of the Paintings, (London, New Haven: Yale University Press, 2004).

Bevan 1979: Bryan Bevan, Charles II's Minette: Princess Henriette-Anne, Duchess of Orleans, (London: Ascent Books, 1979).

Bird y Clayton 2018: Charles II: Art \& Power, ed. Rufus Bird y Martin Clayton, Cat. Exp., Royal Collection, (London: Royal Collection Trust, 2018).

Buvelot 2012: Quentin Buvelot, "Een bijzonder portret van Maria Stuart door Adriaen Hanneman in het Mauritshuis", en Face Book. Studies on Dutch and Flemish Portraiture of the 16th-18th Centuries. Liber Amicorum presented to Rudolf E.O. Ekkart on the occasion of his 65th Birthday, eds. Edwin Buijsen, Charles Dumas y Volker Manuth, (Leiden-Den Haag: Charles Dumas, 2012), pp. 373-380.

Cartwright 1894: Julia Cartwright (Mrs Henry Ady), Madame: a life of Henrietta, daughter of Charles I and duchess of Orleans, (London: Seeley, 1894).

Catalogue of the Library 1840: A Catalogue of the Library of the London Institution, systematically classed. Preceded by an historical and bibliographical account of the establishment, vol. II, (London: C. Skipper and East, 1840).

Catalogue of the printed 1873: Catalogue of the Printed Books in the Library of the Faculty of Advocates, vol. II, (Edinburgh: W. Blackwood and sons, 1873).

Catalogus codicum 1862: Catalogus codicum manuscriptorum Bibliothecae Bodleianae ..., Partis quintae, Fasciculus primus, (Oxonii: Typographeo académico, 1862).

Catalogus Schilderkunst 1988: Catalogus Schilderkunst Oude Meesters, eds. Paul Vandenbroeck, Erik Vandamme, Yolande Morel-Deckers, (Antwerpen: Koninklijk Museum voor Schone Kunsten, 1988).

Chesterfield 1829: Philip Stanhope, Earl of Chesterfield, Letters of Philip, second Earl of Chesterfield to several celebrated individuals of the reign of Charles II, James II, William III, and Queen Anne, with some of their replies, (London: E. Lloyd, 1829). 
Cleveland 1982: European paintings of the 16th, 17th, and 18th centuries. (Cleveland: Cleveland Museum of Art, The Museum, 1982).

Daemen-de Gelder y Van der Motten 2009: Katrien Daemen-de Gelder y Jean Pierre Vander Motten, "Peeter Thijs (1624-77) - An Antwerp Portraitist under the Patronage of William Frederick of Nassau-Dietz (1613-64)", Zeitschrift für Kunstgeschichte, 72. Bd., H. 1, (2009), pp. 18-131.

Dorival 1976: Bernard Dorival, Philippe De Champaigne, 1602-1674: La Vie, L'œuvre, et le Catalogue Raisonné de L'œuvre, (Paris: Léonce Laget Libraire, 1976).

Du Rieu 1658: Florent du Rieu, Les tableaux parlans du peintre Namurois, (Namur: Pierre Gerard, 1658).

Echard 1718: Lawrence Echard, The History of England: From the Restoration of King Charles the Second, to the Conclusion of the Reign of King James the Second, and Establishment of King William and Queen Mary, Containing the Space of Near 29 Years, (London: Jacob Tonson, 1718).

Everett Green 1860: Calendar of State Papers, Domestic Series, of the Reign of Charles II: 1660, ed. Mary Anne Everett Green, vol. XVI, (London: H.M. Stationery Office, 1860).

Fierens-Gevaert 1922: Hippolyte Fierens-Gevaert, Musées Royaux des Beaux-Arts de Belgique. Catalogue de la peinture ancienne, (Bruxelles, 1922)

Fierens-Gevaert y Laes 1927: Hippolyte Fierens-Gevaert y A. Laes, Musées Royaux des Beaux-Arts de Belgique. Catalogue de la peinture ancienne, (Bruxelles: Musées royaux des beaux-arts de Belgique, 1927).

Foucart y Henault 1895: Paul Foucart y Maurice Henault, "Une toile de Pierre Snayers", Réunions des Sociétés des Beaux-Arts et des Départements en 1895, (Paris, 1895), pp. 291-326.

Golvers 2016: Noël Golvers, "Note on the Newly Discovered Portrait of Martini", in Martino Martini (1614-1661), Man of Dialogue, Simposio Internacional (Trento, 15/17-10-2014), eds. Luisa M., Paternicò, Claudia von Collani, Riccardo Scartezzini, (Trento: Università degli Studi, 2016), pp. 9-11.

Hartmann 1934: Cyril Hugues Hartmann, Charles II and Madame, (London: W. Heinemann, 1934).

Hartmann 1954: Cyril Hugues Hartmann, The King, My brother, (London: W. Heinemann, 1954).

Inglis-Jones 1994: James Inglis-Jones, "The Battle of the Dunes, 1658: Condé, War and Power Politics", War in History, vol. 1, n 3, (Nov. 1994), pp. 249-277. 
James II, King of England 1821: Memoirs of James the Second, king of England, \&c. \&c.; collected from various authentic sources, (London: Baldwin, Craddock, and Joy, 1821), vol. I.

Kairis 2000: Pierre-Yves Kairis, "Foisonnement et diversité: les peintres du XVIIe siècle", en Un double regard sur 2000 ans d'art wallon, coord. Liliane Sabatini y Martine Ferrante-Hollenfeltz, Cat. Exp. Musée de I'Art Wallon, Liège (Tournai: Renaissance du Livre, 2000), pp. 321-341.

Kairis 2002: Pierre-Yves Kairis, "Le portrait dans le Namurois au XVIIe siècle, en Portraits en Namurois, ed. Jacques Toussaint (Namur: Société archéologique de Namur, 2002), pp. 31-49.

Kairis 2018: Pierre-Yves Kairis, "Various engravers after Charles Wautier", en Michaelina Wautier 1604-1689. Glorifying a Forgotten Talent, dir. Katlijne Van der Stighelen, (Anvers: Rubenshuis-MAS, 2018), pp. 268-276.

London 2017: Charles II. Art and Power, Cat. Exp., Royal Academy (London: Royal collection Trust, 2017).

Millar 1963: Oliver Millar, The Tudor, Stuart and Early Georgian Pictures in the Collection of Her Majesty the Queen, (London: Phaidon Press, 1963).

Millar 1969: Oliver Millar, Later Georgian Pictures in the Collection of Her Majesty the Queen, (London: Phaidon Press,1969).

O'Donoghue 1908: Freeman O'Donoghue, Catalogue of Engraved British Portraits Preserved in the Department of Prints and Drawings in the British Museum, (London: by order of the Trustees, 1908).

Rapin 1726: Paul Rapin de Thoyras, The History of England, vol. II, (London: for James and John Knapton, 1726).

Sanzsalazar 2014: Jahel Sanzsalazar, "Michaelina Wautier y la boda de su hermano: Historia de un retrato identificado", Tendencias del Mercado de Arte, (enero 2014), pp. 90-94.

Sanzsalazar 2018: Jahel Sanzsalazar, "Michaelina Wautier y el enviado español", Tendencias del mercado del Arte, (abril 2018), pp. 88-91.

Sanzsalazar 2018: Jahel Sanzsalazar, "Michaelina Wautier y la incomparable Anna Maria van Schurman: feminismo, arte y erudición en los Países Bajos en el siglo XVII", Tendencias del mercado del arte, (mayo 2018), pp. 86-91.

Sanzsalazar 2018: Jahel Sanzsalazar, "The influence of Others. The Wautiers, David Teniers and the Archduke Leopold Wilhelm's Theatrum Pictorium", en Michaelina Wautier 1604-1689. Glorifying a Forgotten Talent, dir. Katlijne van der Sitghelen, (Anvers: Rubenshuis-MAS, 2018), pp. 6783.

Sanzsalazar 2019: Jahel Sanzsalazar, "La Vocación de San Mateo: ¿obra de Michaelina y Charles Wautier?", Tendencias del mercado del Arte, (mayo 2019), pp. 88-92. 
Sanzsalazar 2020: Jahel Sanzsalazar, "Encarar el miedo: Don Francisco Fernández de la Cueva, VIII duque de Alburquerque (1619-1676), Virrey de Nueva España y de Sicilia; sobre su estancia en Flandes y su retrato por los hermanos Michaelina y Charles Wautier", Philostrato. Revista de Historia y Arte, $\mathrm{n}^{\circ}$ 7, (2020), pp. 61-98.

Scott 1907: Eva Scott, The travels of the King Charles II in Germany and Flanders, 1654-1660, (London: Archibald Company, 1907).

Ter Kuile 1976: Onno Ter Kuile, Adriaen Hanneman, 1604-1671: Een Haags Portretschilder = Adriaen Hanneman, 1604-1671: a Portrait-painter In The Hague, (Alphen aan den Rijn: Canaletto, 1976).

Thomas 1856: F. S. Thomas, Historical Notes 1603-1714, vol. II, (London: G.E. Eyre and W. Spottiswoode, 1856).

Thurloe 1742: John Thurloe, A Collection of the State Papers of John Thurloe, Secretary First to the Council of State, Containing authentic memorials of the English affairs from the year 1638, to the restoration of King Charles II..., (London: for the executor of F. Gyles, 1742).

Turner 1948: Francis Charles Turner, James II, (London: Eyre \& Spottiswoode, 1948 y 1950).

Van den Branden 1872: Jos F. Van den Branden, "Frans Wouters, kunstschilder, 1612-1659", Annales de l'Académie Royale d'Archéologie de Belgique, (1872), pp. 211-212.

Van der Stighelen 2005: Katlijne van der Stighelen, "Prima inter pares: Over de voorkeur van Aartshertog Leopold-Wilhelm voor Michaelina Woutiers (ca 1620-na 1682)", en Sponsors of the past: Flemish art and patronage 1550-1700, Symposium Katholieke Universiteit Leuven, (14-15 December 2001), (Turnhout: Brepols, 2005), pp. 91-116.

Van der Stighelen 2018: Michaelina Wautier 1604-1689. Glorifying a Forgotten Talent, dir. Katlijne van der Sitghelen, Cat. Exp., (Anvers: Rubenshuis-MAS, 2018).

Van der Stighelen 2018: Katlijne van der Stighelen, "Growing up with Eight Brothers", in Michaelina Wautier 1604-1689. Glorifying a Forgotten Talent, dir. Katlijne van der Sitghelen, Cat. Exp., (Anvers: Rubenshuis-MAS, 2018), pp. 14-40.

Van der Stighelen 2018: Katlijne van der Stighelen, "Michaelina's Versatile Hand. A career without Begining or End?", in Michaelina Wautier 16041689. Glorifying a Forgotten Talent, dir. Katlijne van der Sitghelen, Cat. Exp., (Anvers: Rubenshuis-MAS, 2018), pp. 135-152.

Van der Stighelen 2018: Katlijne van der Stighelen, "Portrait of a Commader in the Spanish Army", en Michaelina Wautier 1604-1689, pp. 162-164, cat. 2; "Self-Portrait" en Michaelina Wautier 1604-1689, pp. 166171, cat. 3; "Portrait of the Jesuit Martino Martini", en Michaelina Wautier 
1604-1689, pp. 186-193, cat. 8; "The Mystic Marriage of Saint Catherine", en Michaelina Wautier 1604-1689, pp. 200-203, cat. 10.

Recibido: $8 / 03 / 2020$

Aceptado: $28 / 04 / 2021$ 